Research Paper

\title{
ILL/DD in Japan across the turn of the century- Basic findings about NACSIS-ILL from 1994 to 2005
}

\author{
Syun TUTIYA ${ }^{1}$, Hiroya TAKEUCHI ${ }^{2}$, Yoshinori SATO ${ }^{3}$ and Hiroshi ITSUMURA ${ }^{4}$ \\ ${ }^{1,2}$ Faculty of Letters, Chiba University \\ ${ }^{1}$ National Institute of Informatics \\ ${ }^{3}$ Faculty of Humanities and Social Sciences, Mie University \\ ${ }^{4}$ Graduate School of Library, Information and Media Studies, University of Tsukuba
}

\begin{abstract}
The present article describes basic facts about the interuniversity cooperative library service that has been in practice in Japan since mid-1990s by way of an ILL request message sending system called NACSIS-ILL. The study underlying the article is based on the data recorded by the system from 1994 to 2005. Among major findings are that the "Interlibrary Loan (ILL)" in the Japanese university context is very peculiar in that requests for photocopies of "foreign journal" articles are significantly predominant in 1990s; that, ironically, increase of requests for "domestic journal" articles, including those in nursing science in particular, is becoming conspicuous as if to match the decrease of requests for "foreign journal" articles, most of which have become available online through site licensing under consortial arrangements that began in 2002; that requests for book loan, which have only accounted for a small portion of requests, apparently increased as the union catalog database called NACSIS-CAT grew; that the system is remarkably efficient with the fill rates in lending/supplying constantly high and the average turnaround time generally less than a week; that while the original intention was construction of a mutually beneficiary collaborative system, there have been some libraries that mainly only request and others that mainly only supply, due partly to the existence of "subject foreign journal center" libraries which started in 1970s; and that some small or middle-sized libraries noticeably began to supply in recent years.
\end{abstract}

\section{KEYWORDS}

Interlibrary loan(ILL), university libraries, document delivery services, information policy, NACSIS-CAT, NACSIS-ILL, electronic journals, consortial licensing

\section{Introduction}

The purpose of the present article is to describe basic facts about the interuniversity cooperative library service that has been in practice in Japan since mid1990s by way of an ILL request message sending system called NACSIS-ILL. The ILL service in question was and has been instrumental and made heavy use of in meeting researchers' needs for documents in scien-

Received December 25, 2006; Revised February 20, 2007; Accepted February 20, 2007.

${ }^{1)}$ tutiya@kenon.l.chiba-u.ac.jp, ${ }^{2)}$ hiroya@kenon.l.chiba-u.ac.jp,

${ }^{3)} y s s a t @ h u m a n . m i e-u . a c . j p,{ }^{4)}$ hits@slis.tsukuba.ac.jp

DOI: 10.2201/NiiPi.2007.4.4 tific fields, and particularly so during late 1990s, when Japanese university libraries suffered what we might call the Japanese version of "serials crisis," in which most university libraries continued to cancel their foreign journal subscriptions for reasons subject to further study. In the sections to follow, we will observe that the functionalities designed into the system in its planning stage, which we will describe in the first sections starting with the background history of university library cooperation in Japan, in fact contributed to Japan's research community by helping supply relevant scientific information for researchers and students on campus and 
that the fact is evidenced by the "growth" of the system itself.

In the circumstances where libraries' subscriptions are short of meeting their patrons' needs, it should be safe to say that ILL request data represents a relatively large portion, if not all, of the need on campus for documents, allowing for the assumption that the data will shed light on the changes occurring in the flow of scientific information during the period under study. Although the National Institute of Informatics(NII), an agency that is responsible for operation of NACSISILL, succeeding to the National Center of Science Information Systems(NACSIS), publishes basic statistics on its ILL system, the authors have given further indepth analysis to the NACSIS-ILL log data files from years covering from 1994 to 2005, which were provided by courtesy of NII for the authors' research group, REFORM, funded from 2004 to 2006 by the Grant-in-Aid from Japan Society for Promotion of Science(JSPS). The system tracks and logs all transactions between participating libraries, each record thereof including all relevant dates, responses from would-be supplying libraries, and bibliographical information.

After we describe the background and prehistory of the ILL practices after 1990s, we will present major findings concerning the general trend of the transactions in Sections 3. They are:

(1) that the "Interlibrary Loan (ILL)" in the Japanese university context is very peculiar in that requests for photocopies of "foreign journal" articles are significantly predominant in 1990s;

(2) that, ironically, increase of requests for "domestic journal" articles, including those in nursing sciences in particular, is becoming conspicuous as if to match the decrease of requests for "foreign journal" articles, most of which have become available online through site licensing under consortial arrangements that began in 2002 ;

(3) that requests for book loan, which have only accounted for a small portion of requests, apparently increased as the union catalog database called NACSISCAT grew;

(4) that the system is remarkably efficient with the fill rates in lending/supplying constantly high and the average turnaround time generally less than a week;

(5) that while the original intention was construction of mutually beneficiary collaborative system, there have been some libraries that mainly only request and others that mainly only supply, due partly to the existence of "subject foreign journal center" libraries which started in 1970s; and

(6) that some small or middle-sized libraries noticeably began to supply in recent years.

These findings will be followed by a short conclusion and future study plan.

\section{Background}

\subsection{Prehistory}

Although in early years of Japanese university library activities, librarians were convinced that collection of research materials was the sole function of university libraries, until user services became a focus of library services under influence of library activities in the United States after the Second World War, [1] nevertheless a group of medical university libraries, which formed today's Japan Medical Library Association in 1927, were interested in ILL services and included the issue in the agenda of the Association's first meeting. The Association then discussed the necessity of compilation of a union catalog of serials, and standardization of ILL request form and processing procedure. They published the first edition of Ika daigaku kyodo gakujutsu zasshi mokuroku[Union List of Medical Universities' Scientific Journals] in 1931. It is remarkable that basic mechanism for ILL, consisting of compilation of a union catalog and standardization of ILL procedure, were already realized in very early days of cooperative activities of academic medical libraries in Japan. The Japan Medical Library Association has never ceased to make efforts to improve the quality of ILL service by updating the union catalog, upgrading ILL procedures and introducing telex for request transmission. [7]

The first edition of Gakujutsu zasshi sogo mokuroku [Union List of Scientific Periodicals] was compiled and published by the Monbusho(Ministry of Education) in 1953, with an intention of covering all subjects. Starting only with seven universities contributing their catalogs, the union catalog extended its coverage as revisions were made periodically. After being commissioned to the International Medical Information Center for the 1975 and 1979 editions, the compilation task began to be undertaken for 1980 by the Research Center for Library and Information Science, University of Tokyo, which would later restructured into The National Center of Science Information System(NACSIS) in 1986. The union catalog became the basis of the periodicals file of NACSIS-CAT, a nation-wide bibliographic utility and union catalog of books and serials mainly for academic libraries in Japan, which NACSIS finally hosted. The participating libraries of NACSISCAT include not only university libraries but also libraries attached to inter-university research institutions, national research institutions, and public libraries supported by prefectures or ordinance-designated cities, and others including hospital libraries.

The Union List of Scientific Periodicals was published in print form for many years and later a CD-ROM version was added only for a short limited period. How- 
ever, after "Webcat," which is an online public access union catalog on the Web, launched in 1997, it seems that the majority of usage of the list has shifted from print to online. No Union List in print form was scheduled after the 2000 version.

\section{2 "Foreign Journal Centers": A coordinated collec- tion system for "foreign journals"1)}

In meeting Japanese researchers' demand for foreign documents after the war, Japan as a nation seems to have taken a bipartite approach: At the government level, there were several achieved and merely attempted projects for national centers that would collect and deliver necessary documents while university libraries preferred to make the best use of resources independently collected by individual libraries by arranging a consortial cooperation among them by way of national union catalog databases and effective communication system for resource sharing.

Monbusho, in recognition of the importance of "foreign journals" as information resources for research activities on campus, sided with the university library's thinking about shared collection and, starting in 1977, designated several national university libraries as "foreign journal centers" in the fields of medicine, engineering, agriculture and social sciences/humanities. ${ }^{2}$ The idea is that Monbusho would provide financial assistance for those libraries to subscribe to international journal titles which were not held by the rest of Japanese university library community but which were essential for researchers though not used much enough to qualify for subscription. It should be noted, however, that the system of "foreign journal centers" were not designed to serve as a centralized nationwide document supply system for Japanese university researchers, but mainly to supplement the collections of individual university libraries. University libraries were basically required to build their journal collections that would meet prevalent needs on their campuses, to cooperate in supplying documents mutually, and then turn to the center libraries as if as last resorts. In short, the aim of this policy action was to construct national information infrastructure for research in such a way that all Japanese university libraries could assure researchers of availability

\footnotetext{
1) We quote the expression, foreign journals, because the sense in which it is used is only that such journals are imported from foreign countries and categorized as such in most of the indigenous statistics due to different treatment in the universities' procurement procedures, though they are just international journals.

2) Following libraries have been designated as subject foreign journal centers: Medicine: Medical Library of Tohoku University, Life Science Library of Osaka University, Medical Library of Kyushu University; Engineering: Tokyo Institute of Technology Library, Kyoto University Library; Agriculture: Agricultural Library of the University of Tokyo, Agricultural Library of Kagoshima University; Humanities/Social Sciences: Hitotsubashi University Library, Social Sciences Library of Kobe University.
}

of necessary documents even if their local collections do not provide them with necessary information. It is to be noted that the idea of centralized document delivery like the BLDSC is different from the one in Japan described above.

\subsection{Fee management}

\subsubsection{Pre-Hojinka days}

Japanese national university libraries had problems in processing payment for photocopies efficiently on account of the government's rules of procurement and accounting they had to follow as government's branches. The year 1967 saw a new step forward to improve the situation when Monbusho set force a unified fee per photocopy sheet. In 1978, an offset accounts system was introduced for transactions between national university libraries by Monbusho's decree in order to reduce clerical work involved in frequent and small fee remittances from requesting to supplying libraries. At the same time, the unified order form for photocopy requests between national university libraries was revised, after it was originally set force in 1971. With such adjustments, national university libraries became able to balance their account twice a year. Monbusho also started fee payment moratorium in 1989 in order to loosen the pre-payment requirement in case of national university/inter-university institution libraries providing photocopies for non-national university libraries.

\subsubsection{Post-Hojinka days}

The above-mentioned offset accounts arrangement applied only to national universities and inter-university research institutions, while private universities and others were completely out of the scope. Thus even after the introduction of fee payment moratorium arrangement, hurdles against the growth of transactions between national university and private or local government supported universities libraries remained unsolved, until national universities obtained flexibility in accounting procedures on occasion of Hojinka in 2004. A new offset accounts arrangement was introduced to be utilized by all NACSIS-ILL participating libraries irrespective of the nature of their parent institutions. NII sends accounting statements to the participating institutions for settling their accounts every 3 months. With this new offset accounts arrangement, the burden having been existed between national and non-national institutions mostly disappeared, possibly accounting for part of the growth of the number of transactions.

\subsection{Copyright issues}

One of the issues involved in the practice of ILL/DD is that of copyright. As described above, NACSIS-ILL 
system mediates only messages for requesting photocopies of journal articles from peer university libraries on condition of payment by requesting library of fees for material photocopies and handling/shipping thereof. It does not take care of the transmission of photocopies themselves by any means.

Libraries are responsible for copyright issues concerning reprographic rights, but they are exempt from the payment of copyright fee based on the limitations on copyright holders' rights in Clause 31 of the Japanese Copyright Law, which stipulates noninfringement of rights by libraries which reproduce library materials without copyright holders' permission on conditions that each reproduction is made on occasion of a request by a library user for research and investigation. To be compliant to the law, practice of ILL/DD by libraries is interpreted as a transaction between user and supplying library with the requesting library, merely as a proxy, mediating a request from the user. ${ }^{3)}$ In terms either of library or of law, the Japanese practice is not interlibrary arrangement in the sense of cooperation between libraries. ${ }^{4)}$ In other words, document delivery in the Japanese system could be ironically viewed as a precursory case of user-initiated ILL/DD with indirect route of delivery. ${ }^{5 \text { ) }}$

Those copyright holders pointed out to the association of national university presidents that the two kinds of practices of photocopying in university libraries, namely that of allowing users to photocopy for themselves by using library's photocopying machine and of supplying photocopies of documents requested by users who did not visit and ask the library, are cases of copyright infringement. The Coordination Committee of Japanese University Libraries, which represents Japanese university library community, was delegated to start discussing with them by the association. Claims raised by the copyright holders' side could have led virtually to abandoning "interlibrary" document delivery. The Coordination Committee on the other hand argued for its necessity and contemporary practice worldwide and finally came up with and put forward the interpretation of Japan's ILL practice within the framework of Japanese copyright law. ${ }^{6)}$ During the lengthy discussion, university libraries were unanimously of the

\footnotetext{
3) Strangely enough, Japanese copyright holder organizations want only libraries to play this role as mediators of photocopy request from end users and allow only libraries to send photocopies between each other, with university libraries licensed for free to make use of electronic facilities for transmission.

4) See, for example, the US Copyright Law, Sec. 108(g).

5) See M. Jackson, 2004, shown as citation in the later section.

6) This has become a prevalent interpretation of the ILL/DD practice by libraries since then, but the issue of whether the proxies must be libraries is open. It is the more important given the fact that commercial document suppliers use university libraries as their document sources, without being explicit to libraries why they are eligible for photocopying privileges in universities.
}

same view that ILL/DD by interlibrary arrangement is inevitable for promotion of all scholarly research and education in universities, and worked with the NACSIS in launching and improving the NACSIS-ILL system.

As a result of a series of revitalized discussion after 2000 between the Coordination Committee and a group of copyright holders, who at this time were delegated not by the JRRC but Japan Academic Association for Copyright Clearance(JAACC) and Japan Copyright Licensing System(JCLS), the Coordination Committee finally came to an agreement in 2003 with a majority of copyright holders of scientific and scholarly publications. The upshot of the agreement was that university libraries in Japan were allowed to get involved in interlibrary arrangement without payment of loyalty fee for copyright, either by fax, by attachment to email or whatever, in requesting and receiving photocopies of copyright materials, on condition that libraries assure that end users only receive the material in print form. Fax transmission was a main issue in the discussion as Japanese copyright law grants to the copyright holder the transmission right, which is so called because the user has to get permission from the copyright holder to send copyrighted materials by phoneline or other electric wiring to a large enough group of end users. Fax transmission is considered by a majority of copyright holders and a section in the government in charge of the administration of the law to be a case of transmission in this sense and require copyright holders' permission. University libraries thought this was ridiculous and succeeded in having the delegates agree to the loyalty free permission.

Apparently, there seem to be no legal obstacles against libraries sending libraries ILL/DD messages over the Internet, which practice has been already witnessed, or against them sending "photocopies" in whatever manner. In spite of that, the issue of transmission of digital files of scanned images of copyrighted materials to individual users has not even be on the table, or has been evaded in the face of several attempts to install systems on campus that would enable end users to directly request and receive documents by way of the Internet.

\subsection{Foundation of NACSIS and its services \\ 2.5.1 Background}

The document entitled Kongo ni okeru gakujutsu joho shisutemu no arikata ni tsuite [A Proposal for Academic Information System in Future], [5] which was submitted to Monbusho by the Scientific Research Council in 1980, recommended that the government should establish a national science information system. In the consequence, National Center for Science Information System, abbreviated as NACSIS was founded 
in 1986 in order to serve as center for the System. One of the goals of NACSIS is to provide Japanese university libraries with a bibliographic utility service entitled NACSIS-CAT, which has led to the construction of national union catalog databases for books and serials. In 1992, NACSIS started the service of NACSISILL, which is a communication system for interlibrary loan between requesting and potentially supplying libraries with reference to holding information obtained from NACSIS-CAT union catalog database, to facilitate the ILL activities among university libraries.

\subsubsection{Nature of NACSIS-ILL}

(1) Early days of NACSIS-ILL

As a result of efforts made by Monbusho and university and other subject-based library associations to promote and improve ILL services among university libraries, the number of annual ILL transactions by university libraries reached a level at which automation was strongly required. As Tamura [11] pointed out, ILL requests for photocopies originated from Japanese university libraries to university libraries were 441,513 and to other institutions were 43,623 in 1988. Strong expectation and eager for the improvement of ILL services are observed in Konishi and Kai, [3] and Shibayama, et. al. [10] Kai [8] also analyzed the NACSIS-ILL data in the first year of its service. Based on the result of a questionnaire survey to faculty members, Hashi [2] discussed some problems on request transfer from NACSIS-IR to ILL system.

(2) Total ILL in Japanese universities and NACSISILL's "share"

As of 2005 academic year, 985 institutions comprising not only universities but also research institutes, public libraries and hospitals participated in NACSISILL. [4] 666 of them are universities and 4-year colleges. As the total number of Japanese universities and 4-year colleges is 726 in 2005, [6] $92 \%$ of the universities and colleges have participated in NACSIS-ILL. It was only $42 \%$ in 1992.

The NACSIS-ILL statistics also indicates that 975,850 requests for photocopies and 85,251 requests for book loan were originated from university or 4year college libraries via NACSIS-ILL in 2003 academic year. According to Digaku toshokan jittai chosa kekka hokoku[Library statistics of colleges and universities] issued by MEXT(Ministry of Education, Culture, Sports, Science and Technology), the total number of requests for photocopies by Japanese university libraries is $1,192,291$, and those for book loan is 115,619 in 2003 academic year. [9] In comparing both data, it is found that $82 \%$ of requests for photocopies and $74 \%$ of requests for book loan originated from Japanese university libraries were processed via NACSIS-ILL in 2003.
National Diet Library(NDL) is one of the major sources and filled more than 14,000 requests from Japanese universities sent via NDL-OPAC document order system or traditional mail/facsimile transmission.

\section{(3) External Links}

NACSIS-ILL expanded its services to include request transmission mechanism to the British Library Document Supply Centre (BLDSC) and NDL in 1994 and 1996 respectively. A linkage between NACSISILL and OCLC was also established in 2002, which was followed by a linkage between NACSIS-ILL and Korea Education and Research Information Service(KERIS) in 2004. These external links would assist NACSISILL participating libraries in sending their requests to the major resources outside NACSIS-ILL members, particularly for those not available among university libraries. At the same time, the NACSIS-ILL participating libraries serve as information resources in providing photocopies or lending books to libraries outside Japan.

\section{Analysis and findings}

Fig. 1 shows a sample of NACSIS-ILL log records, which enable us to trace a series of actions taken in process of ordering. Personal information on patrons is eliminated for protection of privacy. The following fields including status of record(STAT), ordering library(OMLID), supplying library(AMLID), bibliographic record identification number(BIBID), ordering date(ODATE), and receiving date(RDATE) are mainly used for counting and calculation in this study. The detailed definition of each field can be obtained from NII website at http://www.nii.ac.jp/CATILL/INFO/newcat/jissou_siyo/table_home.html.

\subsection{Basic findings}

In this section, basic facts about NACSIS-ILL transactions will be shown based on close counting of request records during the period from 1994 to 2005.

\subsubsection{Dominance of photocopy over loan}

Fig. 2 and Table 1 summarize a typically Japanese characteristic in interlibrary cooperation, where the NACSIS-ILL system has been mainly used to facilitate photocopying service between libraries. This could be said to be the more remarkable, given the statistics reported in 1996 survey about ARL libraries, where 51\% of transactions are book loans at research libraries and $39 \%$ book loan at college libraries on average respectively. [12] $]^{7)}$

While the number of requests for photocopies doubled from 492,827 in 1994 to 1,156,080 in 2005, the

\footnotetext{
7) It is also reported that $44 \%$ of mediated ILLs(those requested to the potential supplying libraries via librarians of the requesting libraries) are for book loan in ARL's 2002 survey. [13]
} 


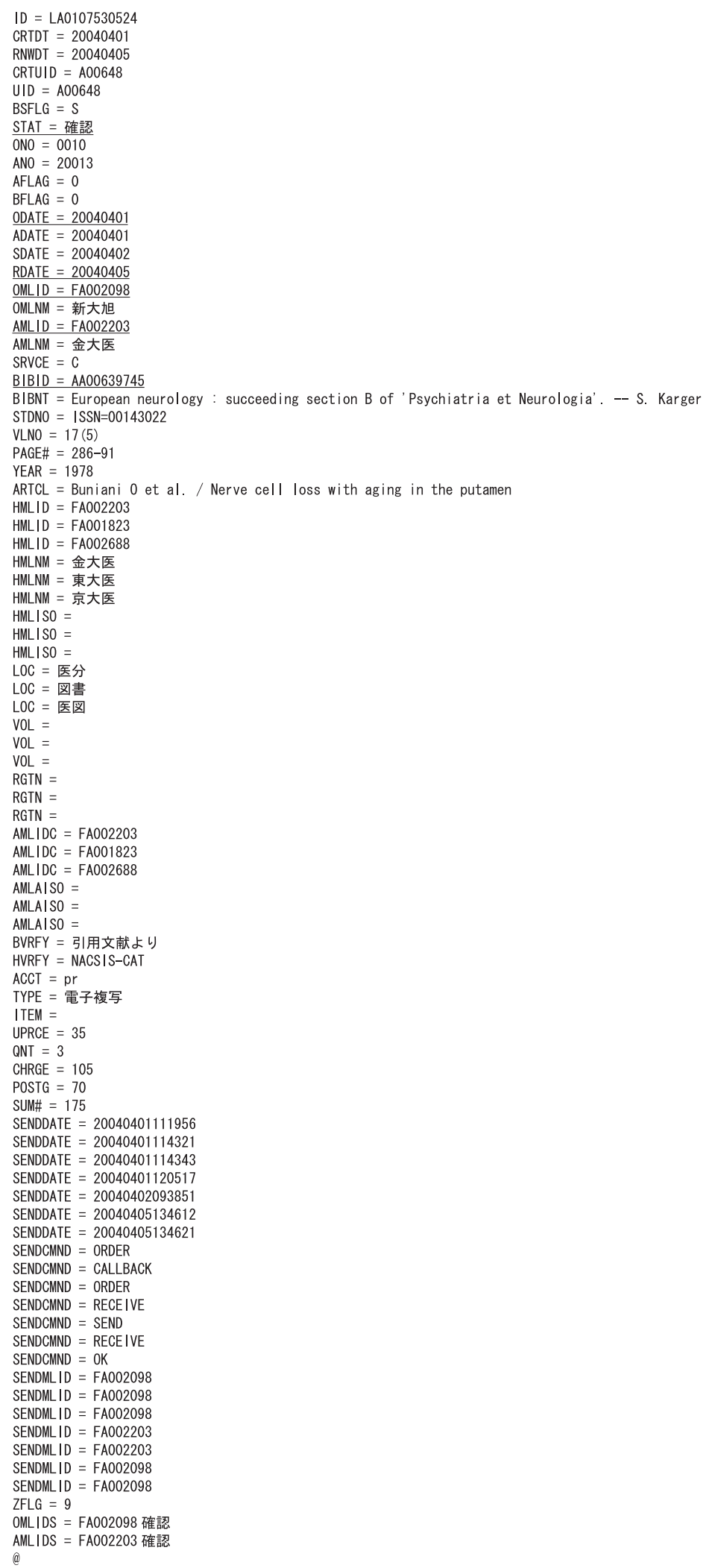

Fig. 1 Sample of NACSIS-ILL log record.

Note: Fields mainly used in the analysis are highlighted by underlines. 


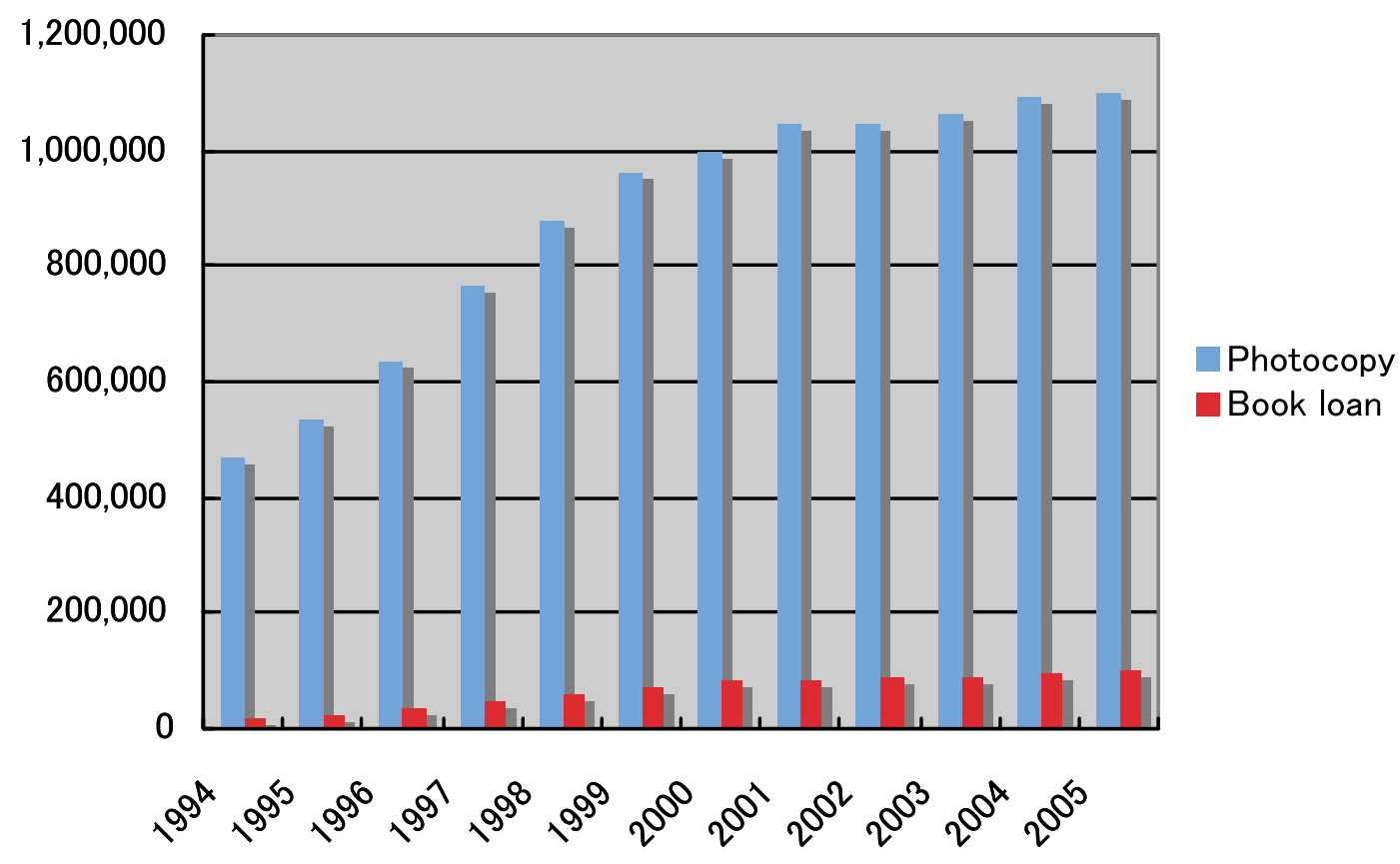

Fig. 2 Requests for book loans and photocopies, 1994-2005.

Table 1 Summary of NACSIS-ILL transactions, 1994-2005.

\begin{tabular}{|c|c|c|c|c|c|c|c|c|c|c|c|}
\hline \multirow[b]{2}{*}{ Year } & \multicolumn{4}{|c|}{ Photocopy requests } & \multicolumn{4}{|c|}{ Book loan requests } & \multicolumn{3}{|c|}{ Total } \\
\hline & Filled & Cancelled & Total & Fill rate & Filled & Cancelled & Total & Fill rate & Completed & Others* & Total \\
\hline 1994 & 468,321 & 24,506 & 492,827 & $95.0 \%$ & 19,373 & 3,855 & 23,228 & $83.4 \%$ & 516,055 & 20 & 516,075 \\
\hline 1995 & 535,229 & 28,467 & 563,696 & $94.9 \%$ & 26,414 & 4,735 & 31,149 & $84.8 \%$ & 594,845 & 38 & 594,883 \\
\hline 1996 & 637,860 & 34,096 & 671,956 & $94.9 \%$ & 35,113 & 5,906 & 41,019 & $85.6 \%$ & 712,975 & 1 & 712,976 \\
\hline 1997 & 768,598 & 38,631 & 807,229 & $95.2 \%$ & 46,319 & 7,547 & 53,866 & $86.0 \%$ & 861,095 & 1 & 861,096 \\
\hline 1998 & 881,786 & 44,436 & 926,222 & $95.2 \%$ & 59,826 & 9,174 & 69,000 & $86.7 \%$ & 995,222 & 16,987 & $1,012,209$ \\
\hline 1999 & 960,456 & 52,551 & $1,013,007$ & $94.8 \%$ & 72,988 & 11,324 & 84,312 & $86.6 \%$ & $1,097,319$ & 1,373 & $1,098,692$ \\
\hline 2000 & $1,000,412$ & 59,894 & $1,060,306$ & $94.4 \%$ & 81,554 & 11,720 & 93,274 & $87.4 \%$ & $1,153,580$ & 2,858 & $1,156,438$ \\
\hline 2001 & $1,045,082$ & 64,373 & $1,109,455$ & $94.2 \%$ & 82,521 & 11,631 & 94,152 & $87.6 \%$ & $1,203,607$ & 12,068 & $1,215,675$ \\
\hline 2002 & $1,045,366$ & 68,076 & $1,113,442$ & $93.9 \%$ & 87,324 & 12,191 & 99,515 & $87.7 \%$ & $1,212,957$ & 19,282 & $1,232,239$ \\
\hline 2003 & $1,061,378$ & 63,572 & $1,124,950$ & $94.3 \%$ & 91,387 & 12,021 & 103,408 & $88.4 \%$ & $1,228,358$ & 14,353 & $1,242,711$ \\
\hline 2004 & $1,092,116$ & 60,428 & $1,152,544$ & $94.8 \%$ & 96,078 & 11,354 & 107,432 & $89.4 \%$ & $1,259,976$ & 5,284 & $1,265,260$ \\
\hline 2005 & $1,099,744$ & 56,336 & $1,156,080$ & $95.1 \%$ & 100,668 & 11,877 & 112,545 & $89.4 \%$ & $1,268,625$ & 23,503 & $1,292,128$ \\
\hline
\end{tabular}

Note 1: The figures in basic statistics are slightly different from NACSIS-ILL statistics available from NII webpage. Probably due to the treatments of the records which were processed nest or later years.

Note 2: "Others" include the records in the status of neither filled nor cancelled, i.e. those in the middle of transaction when the log records were captured.

number of requests for book loans, more remarkable increased nearly five times as many from 1994 to 2005 , with 23,228 in 1994 and 112,545 in 2005. The proportion of book loan to photocopy was 1:20 in 1994, which increased to approximately 1:10 in 2005. In spite of the general predominance of requests for photocopy, this remarkable increase of those for book loan is to be noted at the same time, to fully understand the sta- tus quo of the information resources on Japanese campuses.

Historically speaking, the number of requests for photocopies in 1994 is close to that of requests from university libraries reported in the late $80 \mathrm{~s}$, when the system was not installed yet. That would lead to a tentative hypothesis that most of requests from university libraries began to be sent by way of NACSIS-ILL at the 
start of the system, though it is too early to conclude so because there has been no analysis of the situations either in the 80's or after the system started working about requesting libraries as a whole and the kinds of journals in which requested articles were published.

\subsubsection{Good fill rates for photocopy}

Fill rate here is the percentage of successfully filled requests to all transactions in the year. To calculate this figure for each year, the values of the "STAT" field in the log records were checked. A record with "STAT = [KAKUNIN]" is a photocopy request which is appropriate filled and completed, with photocopies of the requested pages being received by the borrowing library, and its arrival confirmed by the library, and one with "STAT = [HENKYAKUKAKUNIN]" is a book loan request filled. ${ }^{8)}$ A request is unfilled if its value is "CANCEL."

The data tabulated in Table 1 show that, while NACSIS-ILL system was efficiently employed by libraries to supply necessay documents to end users, books were not shared among end users with maximal benefits, though no worse than with ARL libraries. The fill rate for photocopy requests stayed between $93.9 \%$ and $95.2 \%$ from 1994 to 2005 . These figures are better than those observed with the ARL member libraries, where the average borrowing fill rate for photocopy is $86 \%$ for research libraries and $91 \%$ for college libraries respectively. On the other hand, the fill rate for book loan was between $83.4 \%$ and $89.4 \%$ for the same period. These figures are about the same as or lower than the fill rate observed in ARL member libraries, where the corresponding figure for book loan is $83 \%$ with research libraries and $90 \%$ with college libraries. [12] ARL's recent survey indicated that borrowing fill rate for mediated ILL is as high as $86 \%$. [13]

\subsubsection{Requests for "domestic journal" overtaking those for "foreign journal" in 2005}

As described in Section 2, meeting researchers' need for articles published in "foreign journals" has been one of the major policy issues for university libraries in Japan. Counting was therefore made to know the relation between the number of requests for "domestic journal" articles and that for "foreign journal" articles, in case of photocopy requests, based on the values of the BIBID field in each ILL record, where "AN" is prefixed to Japanese language journals and "AA" to foreign language ones. This distinction does not always correspond to the intuitive distinction between "foreign jour-

\footnotetext{
8) In the raw logging data, [KAKUNIN] and [HENKYAKUKAKUNIN] are represented in Chinese characters, which mean "Confirmed" and "Return Confirmed," respectively, while "Cancel" is spelled "CANCEL" in the Latin alphabet.
}

nals" and "domestic journals." "AA" may include journals in English language being published domestically in Japan, and "AN" those in Japanese language published outside Japan. However, it is estimated by running through parts of the logs that the number of such journals should be small enough not to affect quantitative generalization.

Serious consideration, though, should be given to the number of the journals with AA-prefixed journals published in Japanese language, because NACSIS integrated the two bibliographic files for Japanese and foreign language journals in 1997 so that all the bibliographic records for serials created afterwards have prefixed with "AA." Preliminary processing was required to identify Japanese language journals with "AA," and replace the prefix with a different one, "AX" in this case. A list of the BIBIDs with "AA" for the journals whose values of the field called TXTL, standing for "text language" include "jpn," standing for Japanese, was created from the NACSIS-CAT file and was provided for the authors by courtesy of NII. This list was used to check against the BIBIDs in all ILL log records to replace the "AA" with "AX" in the journals in question. The number of records with the resulting "AX"prefixed BIBIDs amounts to 355,888 . Our calculation hereafter is based on this preprocessed BIBIDs.

Fig. 3 demonstrates a remarkable fact that the number of photocopy requests for articles published in foreign journals started to decline from 2000 onward after it rose constantly from the first year of the system operation till 1999. As shown in Table 2, the number of photocopy requests for articles published in foreign journals was 350,609, accounting for $79 \%$ in 1994 , with 91,761 for those published in domestic journals. The number peaked in 1999 with 666,562 requests, about $75 \%$ of all requests for journal articles, but it became 660,959 in $2000,648,218$ in 2002, and fewer in later years. Requests for articles published in domestic journals, on the other hand continue to increase up to 2005, which year saw the watershed when the number of requests for articles published in domestic journals, 520,807, finally exceeded that for foreign journals, 498,594. ${ }^{9)}$ Behind the apparent stable and slow increase of the total number of requests for photocopies, a significant change was taking place in terms of the characters of researchers' need for information. In Section 4, we will discuss related facts which could be viewed as possible causes of this change.

\footnotetext{
9) There are 113,710 records with "AX"-prefixed BIBID, so, given the differece between the number of "AA"-prefixed record and the number of "AN"-prefixed record, this preprocessing can be said to lead to this discovery.
} 


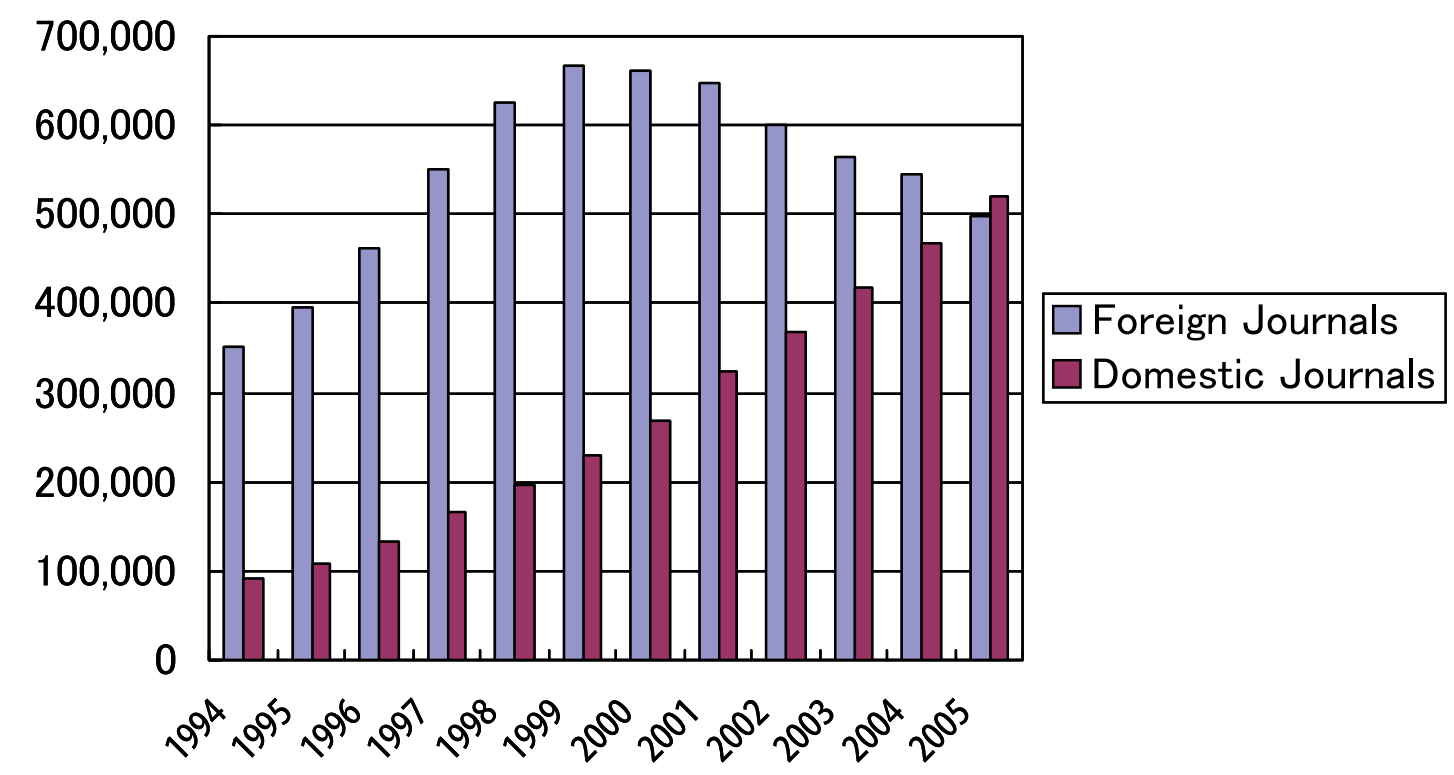

Fig. 3 Number of requests for articles published in foreign journals and domestic journals.

Table 2 Number of requests for photocopy.

\begin{tabular}{|c|c|c|c|c|c|c|c|c|c|c|c|c|}
\hline & 1994 & 1995 & 1996 & 1997 & 1998 & 1999 & 2000 & 2001 & 2002 & 2003 & 2004 & 2005 \\
\hline Foreign Journals & 350,609 & 396,590 & 462,107 & 550,646 & 625,840 & 666,562 & 660,959 & 648,218 & 599,727 & 563,842 & 543,935 & 498,594 \\
\hline Domestic Journals & 91,761 & 108,016 & 132,855 & 166,181 & 195,542 & 228,597 & 268,924 & 322,348 & 368,671 & 416,946 & 468,623 & 520,807 \\
\hline BIBID="AX" & 173 & 146 & 148 & 370 & 1,624 & 4,990 & 13,733 & 26,555 & 41,860 & 62,787 & 89,792 & 113,710 \\
\hline $\mathrm{BIBID}=" \mathrm{AN} "$ & 91,588 & 107,870 & 132,707 & 165,811 & 193,918 & 223,607 & 255,191 & 295,793 & 326,811 & 354,159 & 378,831 & 407,097 \\
\hline BIBID $=$ empty & 3,464 & 3,996 & 6,287 & 7,017 & 7,066 & 7,772 & 8,429 & 9,723 & 11,369 & 11,137 & 13,118 & 13,113 \\
\hline Others* & 22,487 & 26,627 & 36,611 & 44,754 & 53,338 & 57,525 & 62,100 & 64,793 & 65,599 & 69,453 & 66,440 & 67,230 \\
\hline Total & 468,321 & 535,229 & 637,860 & 768,598 & 881,786 & 960,456 & $1,000,412$ & $1,045,082$ & $1,045,366$ & $1,061,378$ & $1,092,116$ & $1,099,744$ \\
\hline
\end{tabular}

Note: "Others" include the records containing other prefixes than AA, AN, and AX in BIBID field.

\subsubsection{High concentration of requests on a small num- ber of journals}

Fig. 4 shows that the top $5 \%$ of all requested journals accounted for nearly half of requests for journal articles in 2005. Those were 2,677(1407 domestic and 1270 foreign) journals. On the other hand, 14,198(6,021 domestic and 8,177 foreign) journals were requested only once, that is only one article of each, in the same year. All that shows the high concentration of requests on a small number of journals, with an assumption in mind that the larger number of requests does not necessary mean lack of information but only lack of information in researchers' environments. With this generally high concentration, though, increasingly visible difference between foreign and domestic journal situations can be illustrated by calculating the ratio of the numbers of requests in the two genres for articles published in the 300 journals which were most often requested each year. The ratio of the number of requests for articles in top 300 foreign journal titles to the total number of requests for foreign journals articles decreased from $27.2 \%$ in 1994 to $20.2 \%$ in 2005, while top 300 domestic journal titles, which were not necessarily the same titles every year, have almost constantly explained 24 $\%$ of requests from 1994 through 2005.

\subsubsection{Demands which have grown and those which have fallen}

Table 3 lists the top 25 journal titles whose articles were most requested each year in the descending order according to the number of requests. There are no Japanese titles up to 2001 in this list, but since 2002 they have been increasingly visible, with 18 out of 25 titles being domestic in 2005. A closer look reveals an interesting fact that Japanese journals in the table are, in the most part, published in fields related to nursing, counseling, ageing, while foreign journals which were in urging demand in the 90s are mainly either in medicine/life science or in chemistry and material science. Sorting out all journals in terms of their subject 


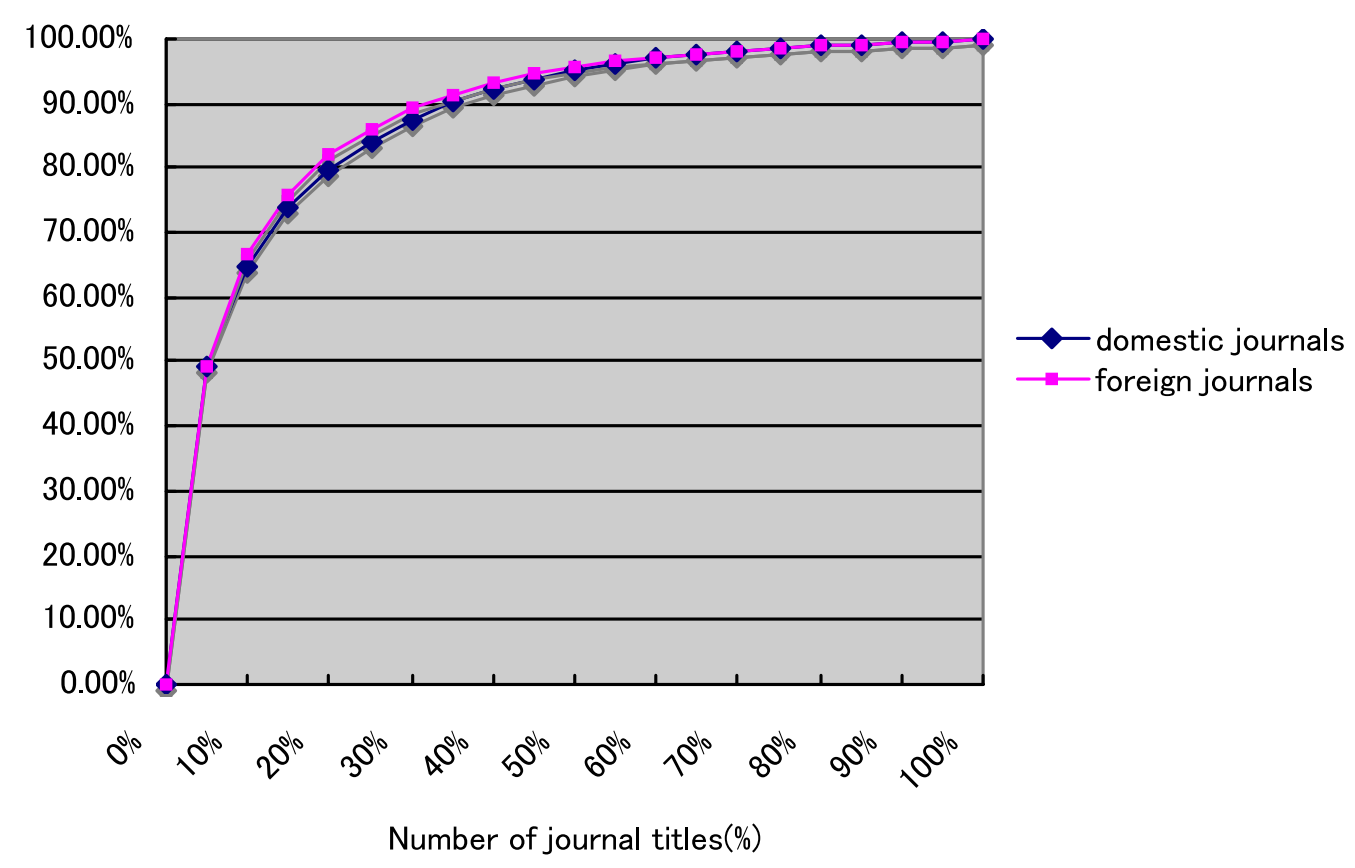

Fig. 4 Cumulative frequency diagram for domestic and foreign journals in 2005.

classification is so difficult beyond the scope of this article that a further study is to be done, but this intuitive tradeoff in terms of subject genres may help understand the change in the number of requests for foreign and domestic journals reported above.

\subsubsection{Number of demands by the participating libraries}

Table 4 shows top 10 libraries in terms of numbers of filled requests they sent out. The majority of them are medical libraries in national universities up until 2000, but they gradually disappeared from the list after the year. Some medical libraries still remain, sending out a large number of requests, but the number of requests from them is observed to have dropped. It is to be noted that even after the medical libraries in national universities disappeared from the list, the majority of top 20 libraries are medical/hospital libraries or those related to life science.

Typically, those hospital libraries include the Library of Japan Medical Association(JMA), which is the legally defined association of government-certified medical doctors, and the KKR Central Library in Toranomon Hospital, which is the flagship hospital of the Kokka Koumuin Kyosai Kumiai Rengoukai, an aggregation of corporations for cooperative health insurance and social security for employees of the national government and of the independent administrative and similar agencies. The disappearance of the medical library of Kyushu University from the list in 1999 is a result of the cessation of the part of JICA(Japan International Corporation Agency)-funded SEAMIC (Southeast Asia Medical Information Center) operation hosted by the Kyushu University Medical Library. SEAMIC aimed at providing medical information for Southeast Asian countries by delivering requested documents free of charge, with a large part of the requests actually not filled by the Kyushu University library being forwarded to participating libraries in NACSIS-ILL system. ${ }^{10)}$

The chronological changes in the number of requests from selected libraries in Fig. 5 demonstrate different tendencies in different kinds of libraries, though in most libraries of multi-faculty universities the tendencies are not clearly discernible. While requests from medical or engineering libraries attached to national universities continues to decline after 2000, those from general or social science/humanities libraries in national universities (Tsukuba and Tohoku, for example) do not exhibit a decline in the same period. This could be viewed as indicative of different tendencies in different subject fields. Although full analysis in terms of subject

\footnotetext{
10) According to the data provided by courtesy of the Kyushu University Library, 8,236 out of 10,766 requests and 10,861 out of 12,179 requests sent from Southeast Asian countries were forwarded in 1998 and 1999, respectively. These requests account for more than $60 \%$ of the requests made by the library each year. As will be shown in the next section, this library is a major provider of medical information in the NACSIS-ILL system. After JICA funding stopped, document delivery operation of SEAMIC was transferred to the Toho University Library, but fee payment seems to have discouraged Southeast Asian countries from using the system, decreasing the size of transaction.
} 


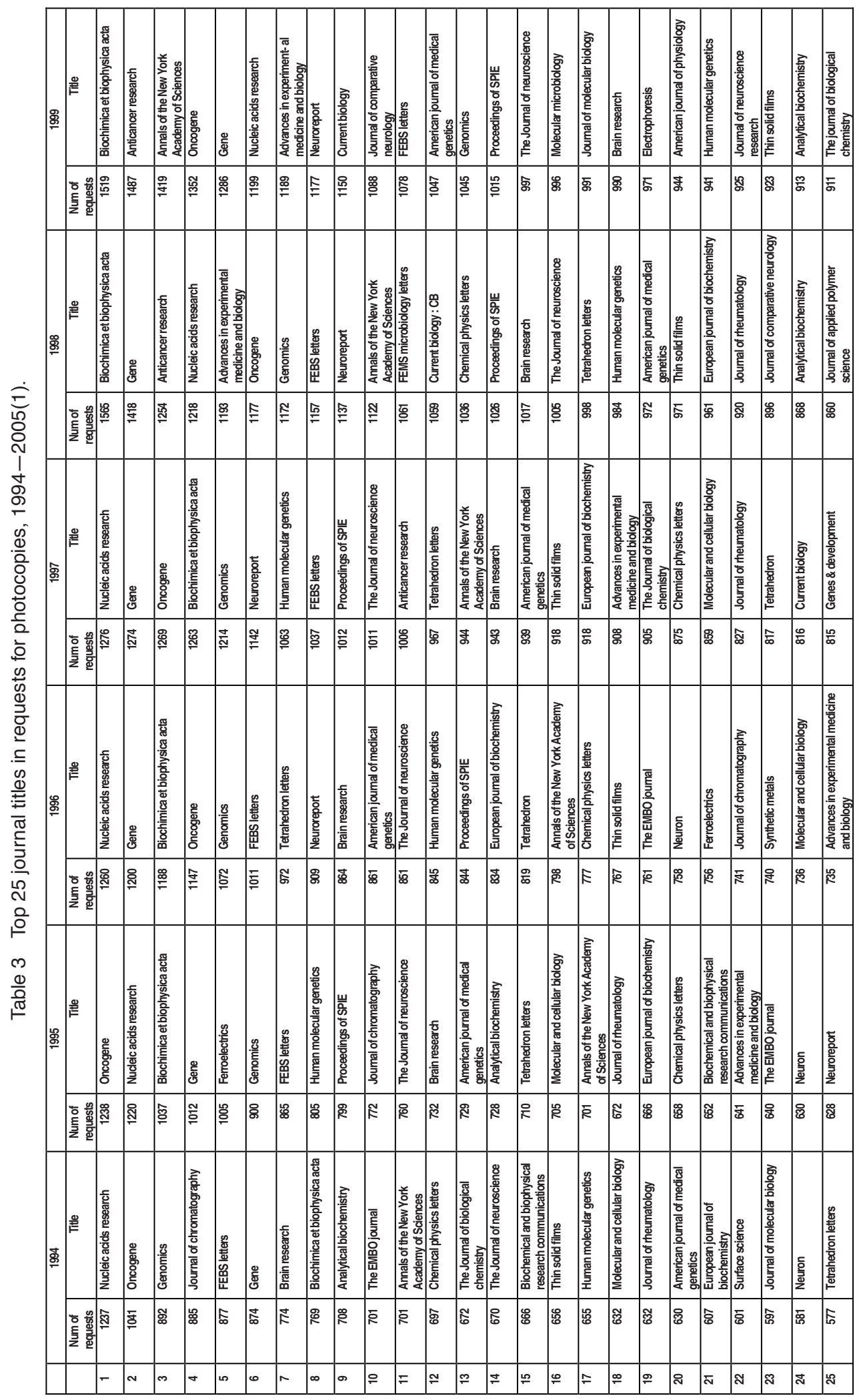




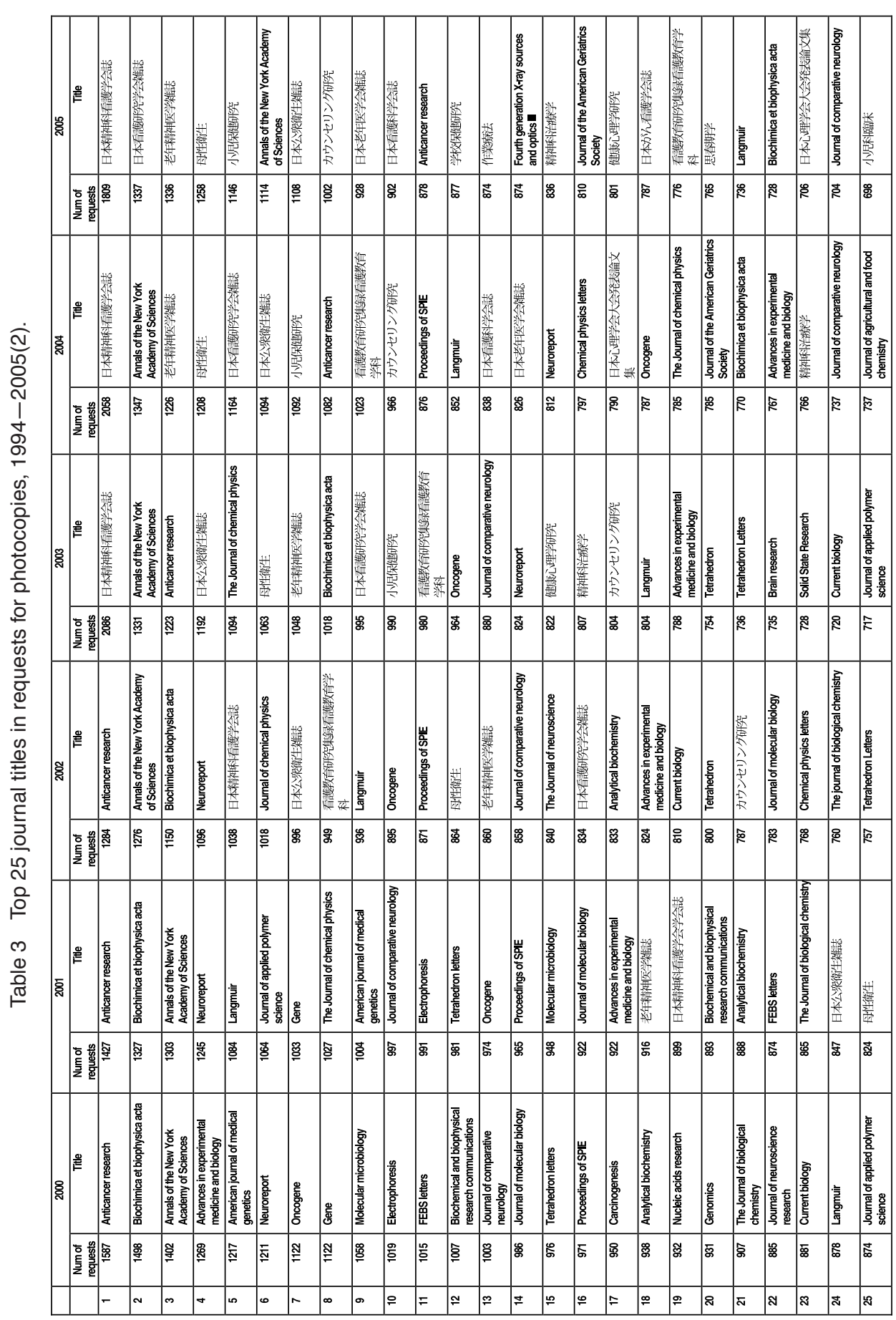

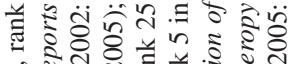

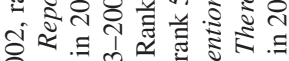

त

छ

… «.

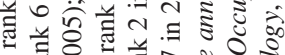

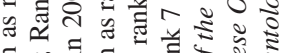

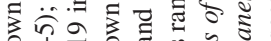

은

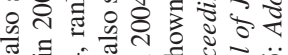

ब.

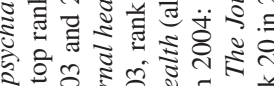

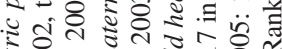

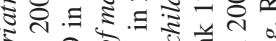

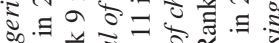

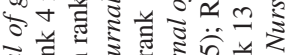

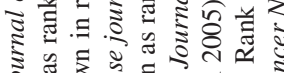

5.

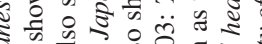

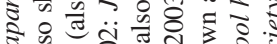

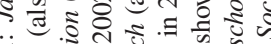

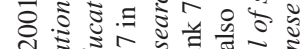

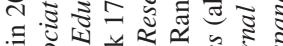

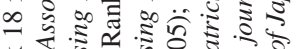

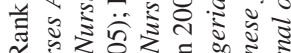

ن

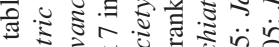

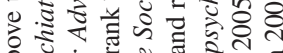

के

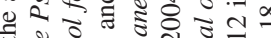

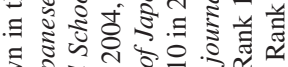

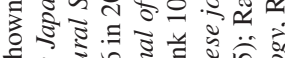

कू

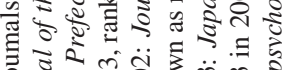

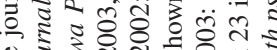

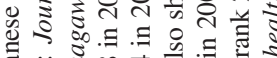

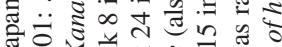

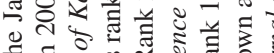

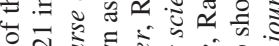

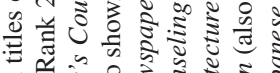

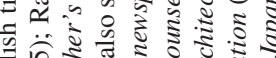

60. 영

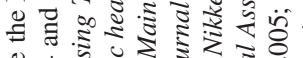

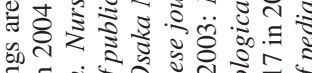

.

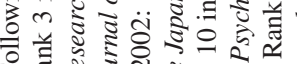

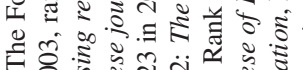

Fित्र

แnt. 
Table 4 Top 10 of requesting libraries (photocopies).

\begin{tabular}{|c|c|c|c|c|c|c|c|c|c|c|c|}
\hline \multicolumn{2}{|c|}{1994} & \multicolumn{2}{|c|}{1995} & \multicolumn{2}{|c|}{1996} & \multicolumn{2}{|c|}{1997} & \multicolumn{2}{|c|}{1998} & \multicolumn{2}{|c|}{1999} \\
\hline \begin{tabular}{l|l}
$1 \mid$ Kyushu. Med. \\
\end{tabular} & 10,685 & 5 Kyushu. Med. & 10,287 & 7 Kyushu. Med. & 11,791 & Kyushu. Med. & 13,831 & 1 Kyushu. Med. & 15,551 & JMA Library & 10,925 \\
\hline $\begin{array}{l}2 \text { Nagasaki. Med. } \\
\end{array}$ & 7,054 & $\begin{array}{l}4 \text { Nagasaki. Med. } \\
\end{array}$ & 8,333 & 3 Nagasaki. Med. & 7,959 & 9 Nagasaki. Med. & 9,887 & 7 JMA Library & 9,888 & Okayama & 9,832 \\
\hline \begin{tabular}{l|l} 
Kagoshima.Med. \\
\end{tabular} & 6,023 & 3 Tsukuba & 6,323 & 3 JMA Library & 7,698 & J JMA Library & 9,082 & 2 Nagasaki.Med. & 9,715 & Tsukuba & 9,598 \\
\hline \begin{tabular}{l|l|}
5 & Toyohashi S\&T \\
\end{tabular} & 5,659 & 9 Oita Medical U & 6,093 & \begin{tabular}{l|l|}
3 Kagoshima.Med \\
\end{tabular} & 6,825 & Hiroshima. Med. & 8,160 & 0 Tsukuba & 8,441 & Hiroshima Med. & 9,217 \\
\hline 6 Oita Medical U & 5,569 & $\begin{array}{l}9 \text { Kagoshima Med. } \\
\end{array}$ & 6,045 & 5 Oita Medical U. & 6,821 & Tsukuba & 8,021 & 1 Kagoshima.Med. & 8,263 & Hamamatsu Med. & 8,975 \\
\hline 7 Kyoto. Med. & 5,396 & \begin{tabular}{l|l}
6 Kagoshima \\
\end{tabular} & 5,905 & $\begin{array}{l}5 \text { Mie } \\
\end{array}$ & 6,309 & Hamamatsu Med. & 7,987 & \begin{tabular}{l|l}
7 Hamamatsu Med. \\
\end{tabular} & 8,090 & Niigata & 7,955 \\
\hline $\begin{array}{l}8 \\
\end{array}$ & 5,272 & 2 Gifu & 5,648 & \begin{tabular}{|l|l}
8 Akita. Med. \\
\end{tabular} & 6,288 & Kyoto. Med. & 7,448 & 8 Okayama & 8,035 & Oita Medical U. & 7,929 \\
\hline
\end{tabular}

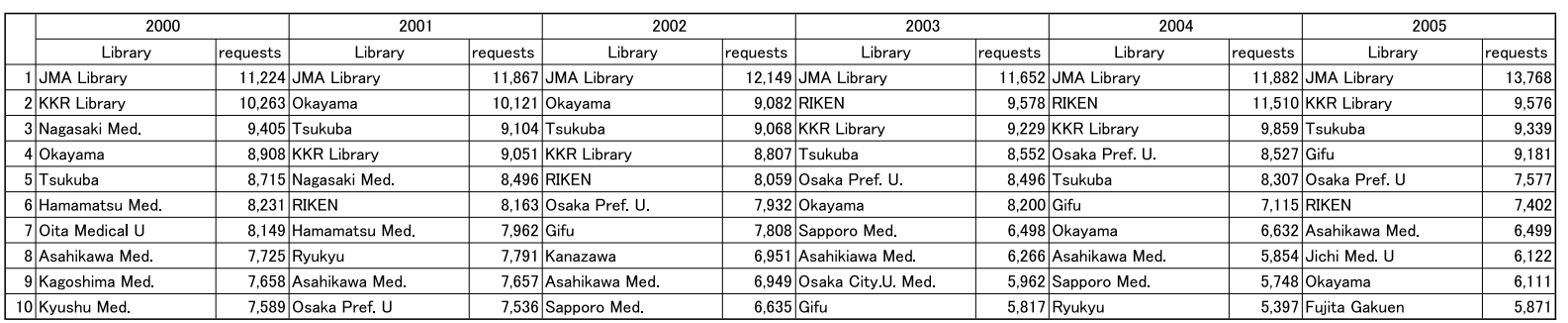

JMA Library: Japan Medical Association Library.

KKR Library: Kokka Koumuin Kyosai Kumiai Rengoukai Central Library (Attached to Toranomon Hospital).

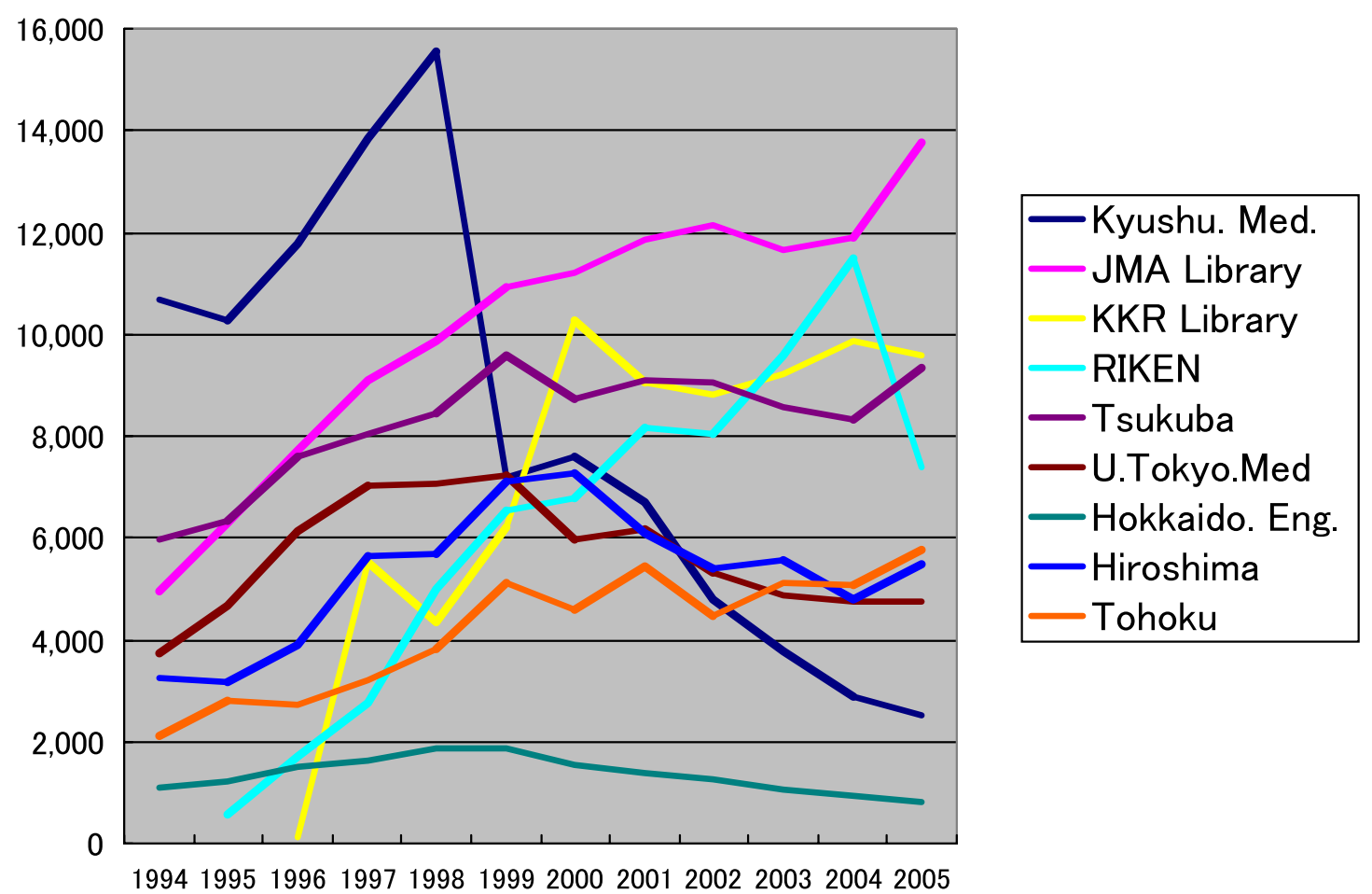

Fig. 5 Chronological changes in number of photocopy requests by some selected libraries.

fields is beyond the scope of this article, the observations made in this section should allow us to state generally that the needs the NACSIS-ILL was originally designed to help libraries meet and did actually fulfill in the 1990s have changed in the 21 th century.

\subsubsection{Number of supply by participating libraries}

Table 5 shows top 10 libraries in terms of numbers of documents they provided for 1994-2005. Fig. 6 demonstrates the chronological changes of supply made by some selected libraries. The Life Sciences Library of Osaka University has held its powerful posi- 
Table 5 Top 10 of supplying libraries (photocopy).

\begin{tabular}{|r|l|r|l|l|l|l|l|l|l|l|l|l|}
\hline & \multicolumn{2}{|c|}{1994} & \multicolumn{2}{c|}{1995} & \multicolumn{2}{c|}{1996} & \multicolumn{2}{c|}{1997} & \multicolumn{2}{c|}{1998} & \multicolumn{2}{c|}{1999} \\
\cline { 2 - 11 } & Library & Supply & Library & Supply & Library & Supply & Library & Supply & Library & Supply & Library & Supply \\
\hline 1 & Osaka. LifeSci. & 28,528 & Osaka. LifeSci. & 32,484 & Osaka. LifeSci. & 36,249 & Osaka. LifeSci. & 43,957 & Osaka. LifeSci. & 50,129 & Osaka. LifeSci. & 42,445 \\
\hline 2 & Tokyo Inst. Tech. & 18,354 & Tokyo Inst. Tech. & 21,660 & Tokyo Inst. Tech. & 23,646 & Tokyo Inst. Tech. & 25,571 & Tokyo Inst. Tech. & 22,079 & Kyushu. Med. & 24,591 \\
\hline 3 & Tohoku. Med. & 13,015 & Tohoku. Med. & 12,048 & Kyushu. Med. & 13,612 & Kyushu. Med. & 18,473 & Kyushu. Med. & 20,377 & Tokyo Inst. Tech. & 21,643 \\
\hline 4 & U.Tokyo. Agri. & 8,858 & U.Tokyo. Agri. & 9,072 & Tohoku. Med. & 12,728 & Tohoku. Med. & 17,993 & Tohoku. Med. & 19,670 & U.Tokyo.Agri. & 20,189 \\
\hline 5 & Yamaguchi. Med. & 8,411 & U.Tokyo. General & 8,960 & U.Tokyo. Agri. & 11,024 & Kanazawa. Med. & 12,319 & U.Tokyo.Agri. & 17,397 & Tohoku. Med. & 19,876 \\
\hline 6 & Kyushu. Med. & 7,403 & Kanazawa. Med. & 8,933 & NDL & 9,960 & U.Tokyo. Agri. & 11,995 & NDL & 16,735 & NDL & 16,733 \\
\hline 7 & U.Tokyo. General & 7,139 & Kyushu. Med. & 8,623 & Kyoto. Med. & 9,643 & NDL & 11,939 & Kyoto. Med. & 12,801 & Kyoto. Med. & 13,637 \\
\hline 8 & U.Tokyo.Med. & 6,391 & Kyoto & 8,521 & Kanazawa. Med. & 9,421 & Kyoto. Med. & 11,565 & Kanazawa. Med. & 12,516 & U.Tokyo.Med & 11,113 \\
\hline 9 & Kyoto. Med. & 6,022 & Kyoto. Med. & 8,319 & Kyoto & 9,309 & Kyoto & 10,942 & U.Tokyo.Med & 11,380 & Nagoya. Med. & 10,920 \\
\hline 10 & Tsukuba & 5,841 & Yamaguchi. Med. & 7,663 & U.Tokyo. General & 9,097 & U.Tokyo. General & 10,563 & Nagoya & 9,447 & Kanazawa. Med. & 10,543 \\
\hline
\end{tabular}

\begin{tabular}{|c|c|c|c|c|c|c|c|c|c|c|c|c|}
\hline & \multicolumn{2}{|l|}{2000} & \multicolumn{2}{|l|}{2001} & \multicolumn{2}{|l|}{2002} & \multicolumn{2}{|l|}{2003} & \multicolumn{2}{|l|}{2004} & \multicolumn{2}{|l|}{2005} \\
\hline & Library & Supply & Library & Supply & Library & Supply & Library & Supply & Library & Supply & Library & Supply \\
\hline & Osaka. LifeSci. & 41,776 & Osaka. LifeSci. & 43,373 & Osaka. LifeSci. & 37,603 & Osaka. LifeSci. & 37,263 & Osaka. LifeSci. & 34,661 & Osaka. LifeSci. & 30,314 \\
\hline & Kyushu. Med. & 24,045 & Kyushu. Med. & 24,058 & Kyushu. Med. & 23,384 & NDL & 24,872 & \begin{tabular}{|l} 
Tokyo Inst. Tech. \\
\end{tabular} & 21,198 & \begin{tabular}{l|l} 
Tokyo Inst. Tech. \\
\end{tabular} & 19,397 \\
\hline & $\begin{array}{l}\text { U.Tokyo.Agri. } \\
\end{array}$ & 21,094 & NDL & 20,864 & NDL & 18,912 & Kyushu. Med. & 21,079 & NDL & 19,266 & Tohoku. Med. & 19,101 \\
\hline & $\begin{array}{ll}\text { Tokyo Inst. Tech. } \\
\end{array}$ & 20,989 & U.Tokyo.Agri. & 20,678 & U.Tokyo.Agri. & 18,379 & Tokyo Inst. Tech. & 20,688 & Kyushu. Med. & 16,134 & NDL & 18,001 \\
\hline & NDL & 19,195 & Tohoku. Med. & 17,791 & Tokyo Inst. Tech. & 17,964 & U.Tokyo.Agri. & 15,903 & $\begin{array}{l}\text { Tohoku. Med. } \\
\end{array}$ & 15,101 & Kyushu. Med. & 14,947 \\
\hline & $\begin{array}{l}\text { Tohoku. Med. } \\
\end{array}$ & 17,687 & Tokyo Inst. Tech. & 16,650 & Tohoku. Med. & 15,826 & Tohoku. Med. & 15,434 & Y City U. Med. & 14,140 & Y City U. Med. & 12,141 \\
\hline & Kyoto. Med. & 12,870 & Kyoto & 12,663 & Kyoto & 12,429 & Y City U. Med. & 12,864 & Keio Med. & 12,677 & Keio Med. & 11,085 \\
\hline & Kanazawa. Med. & 11,016 & Kyoto. Med. & 12,593 & Y City U. Med. & 11,128 & Keio Med. & 11,939 & Kyoto. Med. & 10,030 & Kyoto & 9,311 \\
\hline & Kyoto & 10,996 & U.Tokyo.Med & 11,474 & Kyushu & 10,916 & Kyoto & 11,418 & \begin{tabular}{l|l} 
Tokyo Med. U. \\
\end{tabular} & 9,517 & Chiba. Health & 8,605 \\
\hline & Nagoya. Med. & 10,450 & Kyushu & 10,856 & U.Tokyo.Med & 10,712 & U.Tokyo.Med & 10,077 & Kyoto & 9,461 & Tokyo Med. U. & 8,596 \\
\hline
\end{tabular}

Note: Y City U. Med. $=$ Yokohama City University Medical Library.

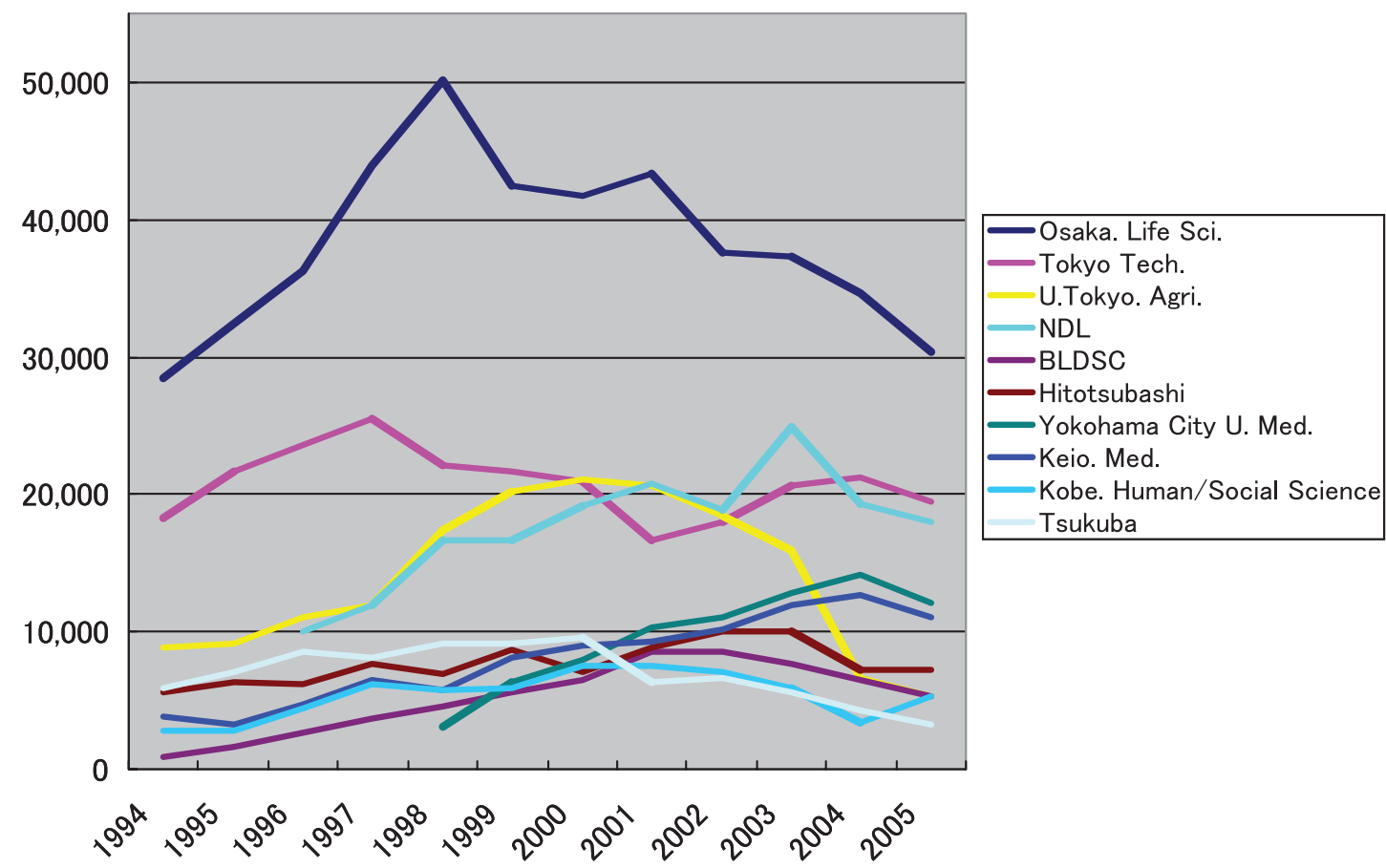

Fig. 6 Chronological changes in number of supply of photocopies provision by some selected libraries.

tion in providing photocopies since 1994, even though the number of document supply has been decreasing, that is, 50,129 in 1998 and 30,314 in 2005. As shown in Table 5, some libraries designated as "subject foreign journal center" and other big libraries have continuously been supplying libraries. Among those libraries, some libraries show remarkable decrease in number of supply in recent years. For example, the number of supply provided by the Agricultural Library of the University of Tokyo, which is one of the "subject foreign journal centers," went down from 21,094 in 2000 to 5,323 in 2005. On the other hand, Tokyo Institute of Technol- 


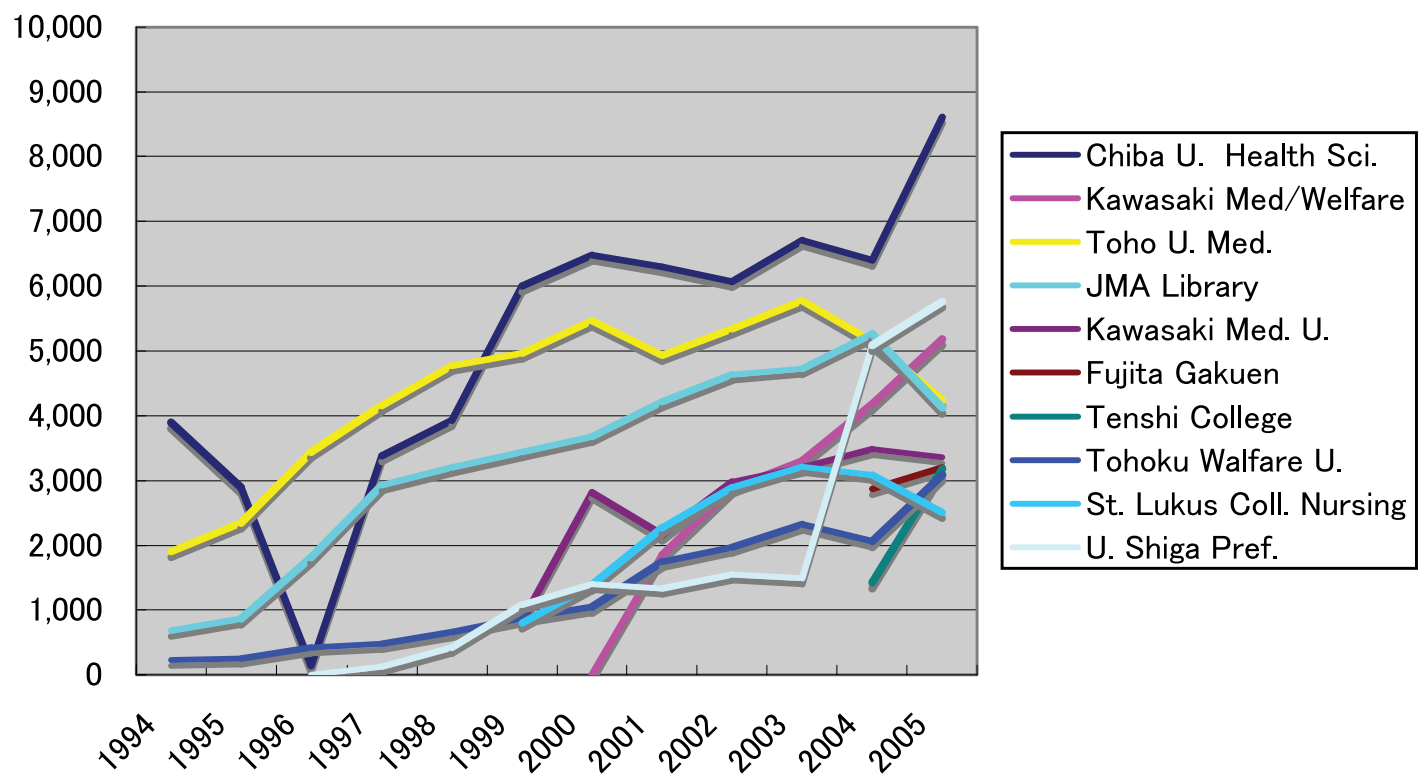

Fig. 7 Newly emerging libraries as major sources for the provision of photocopy.

ogy Library provided with photocopies stably in terms of the number of supply. In general, the number of photocopies these libraries provided was decreasing in recent years.

In comparison with Tables 4 and 5 , it is found that there are some libraries that mainly only request and others that mainly only supply, even though it has been expected that mutually beneficiary collaborative system be constructed among university libraries.

It is also observed that the medical libraries of Keio University and Yokohama City University appeared as major sources of supply in Table 5. ${ }^{11)}$ In addition, a group of libraries, which are small or middle-sized ones, noticeably began to supply photocopies in recent years. For examples, as shown in Fig. 7, the number of supplied documents has doubled in Tenshi College library from 1423 in 2004 to 3185 in 2005 . These libraries are specialized in medical-related subjects including nursing science and social welfare.

\subsubsection{Turnaround time}

Turnaround time is the length of time for borrowing transaction to be filled. In this analysis the length of time for borrowing transactions completed by cancel-

\footnotetext{
11) University libraries have supplied photocopies for Japanese hospitals as well as researchers on campus. The size of demands from hospitals has not been accurately estimated but commonly believed to be substantial based on the number of requests from hospitals received by university libraries, most of which are transmitted by fax. JMLA has a long history of enhancing the functionality of document supply to hospital libraries, but does not cover all hospital libraries so that the statistics can not be exhaustive. Studies are under way to grasp the situation around the information needs at hospitals. See [14] for details.
}

lation, which was also calculated in ARL study, is not included. Turnaround time is indicated as the number of calendar days from the date the request submitted to NACSIS-ILL by library staff to the date the requesting library receives the requested materials. The date the requesting library enters "OK" command for photocopy and "receive" command for book loan, both of which are recorded in NACSIS-ILL log files, are used to estimate the date of arrival of materials.

Tables 6 and 7 summarize the mean and percentile of turnaround time for photocopy and book loan. The mean for photocopy was 8.7 days in 1994, which was improved to 4.9 days in 2005 . The mean for book loan was 10.34 days in 1994 , which was improved to 4.27 days in 2005 as well. The percentile also indicates that effectiveness measured by the turnaround time has been improved. ARL's 1996 survey reported 14.9 days for photocopy and 16.9 days for book loan on average at research libraries, 10.4 days for photocopy and 11.4 days for book loan on average at college libraries. [12] In 2002 survey, it reported that 7.6 days were required for mediated ILL service. [13] It should be noted that the working definition of turnaround time in ARL survey is the time length from the date the patron submitted the ILL request and to the date the patron was notified of the material availability and should be longer than the definition of this study.

The minimum " 0 " day means that document supply is made on the day of request, which is supposed that photocopy was transmitted via fax for express request on the same day, or the request was satisfied by a library 
Table 6 Summary of turnaround time: photocopy.

\begin{tabular}{|c|r|r|r|r|r|r|r|r|r|r|r|r|}
\hline & 1994 & 1995 & 1996 & 1997 & 1998 & 1999 & 2000 & 2001 & 2002 & 2003 & 2004 & 2005 \\
\hline Mean & 8.70 & 8.55 & 8.26 & 8.68 & 8.03 & 8.24 & 7.34 & 7.26 & 6.56 & 5.79 & 5.29 & 4.90 \\
\hline Min. & 0 & 0 & 0 & 0 & 0 & 0 & 0 & 0 & 0 & 0 & 0 & 0 \\
\hline Max & 1,111 & 1,468 & 1,833 & 1,836 & 1,830 & 1,959 & 1,161 & 1,830 & 1,591 & 1,830 & 1,104 & 1,481 \\
\hline 10th percentile & 3 & 3 & 3 & 3 & 3 & 3 & 2 & 2 & 2 & 2 & 2 & 2 \\
\hline 25th percentile & 4 & 4 & 4 & 3 & 4 & 4 & 4 & 3 & 3 & 3 & 3 & 3 \\
\hline 50th percentile & 7 & 6 & 6 & 6 & 6 & 6 & 6 & 5 & 5 & 5 & 4 & 4 \\
\hline 75th percentile & 10 & 10 & 9 & 6 & 8 & 9 & 8 & 8 & 7 & 7 & 6 & 6 \\
\hline 90th percentile & 16 & 16 & 15 & 15 & 14 & 14 & 13 & 12 & 11 & 10 & 9 & 8 \\
\hline 95th percentile & 25 & 23 & 21 & 22 & 20 & 20 & 17 & 16 & 14 & 13 & 12 & 11 \\
\hline
\end{tabular}

Table 7 Summary of turnaround time: book loan.

\begin{tabular}{|c|c|c|c|c|c|c|c|c|c|c|c|c|}
\hline & & & & & & & & & & \multicolumn{3}{|c|}{ (unit=days) } \\
\hline & 1994 & 1995 & 1996 & 1997 & 1998 & 1999 & 2000 & 2001 & 2002 & 2003 & 2004 & 2005 \\
\hline Mean & 10.34 & 9.29 & 8.07 & 7.41 & 6.87 & 6.59 & 6.23 & 5.77 & 5.41 & 4.97 & 4.62 & 4.27 \\
\hline Min. & 0 & 0 & 0 & 0 & 0 & 0 & 0 & 0 & 0 & 0 & 0 & 0 \\
\hline Max & 506 & 368 & 398 & 371 & 867 & 315 & 1,111 & 1,660 & 1,103 & 1,194 & 1,103 & 854 \\
\hline 10th percentile & 3 & 3 & 3 & 3 & 2 & 2 & 2 & 2 & 2 & 2 & 1 & 1 \\
\hline 25th percentile & 5 & 5 & 4 & 4 & 4 & 3 & 3 & 3 & 3 & 2 & 2 & 2 \\
\hline 50th percentile & 7 & 7 & 6 & 6 & 6 & 5 & 5 & 5 & 5 & 4 & 4 & 4 \\
\hline 75th percentile & 12 & 11 & 10 & 8 & 8 & 7 & 7 & 7 & 6 & 6 & 6 & 5 \\
\hline 90th percentile & 21 & 19 & 15 & 14 & 13 & 12 & 11 & 10 & 10 & 8 & 8 & 7 \\
\hline 95th percentile & 28 & 25 & 21 & 18 & 16 & 16 & 14 & 13 & 13 & 11 & 11 & 10 \\
\hline
\end{tabular}

in a different campus of the same university, where intercampus transportation was effectively provided.

\subsection{Factors affecting the observed facts}

\subsubsection{Number of book loan requests}

As described in Table 1 and Fig. 2, requests for book loan have increased stably since 1994 until now. Although in fact the launch in April of 1997, of "Webcat", a web service for the public to access the bibliographical and holding data of NACSIS-CAT with search functionality, might have resulted in increase of requests for book loan, no clear indicator relating installation of Webcat to requests for book loan has been identified. Rather, the Number of requests for book loan strongly correlates to the number of participating institutions of NACSIS-ILL( $\mathrm{r}=0.995)$, number of bibliographic records of books $(r=0.947)$ and holding records of books $(r=0.966)$ in NACSIS-CAT. It is therefore safer to conclude that steady growth in the number of participating libraries by way of NACSIS-CAT/ILL is a major cause of that of requests for book loan.

\subsubsection{Number of photocopy requests}

The constant increase in the 1990s and the apparent stability after 2000 of the total number of photocopy requests could be accounted for by joint contribution of the following three major factors:

1) The growth in photocopy requests until 1999 for articles published in foreign journals may be said to reflect the decrease of the variety, namely the number of the kinds of titles subscribed to, of journals from 1988 to 2000 across Japanese university libraries, which tended to concentrate their collection efforts on "core" journals probably due to steep rise of unit costs of international journals.

2) The decrease of requests after 2000 for articles published in foreign journals can be attributed to the increase in accessibility to journal contents in titles published by major "foreign" publishers, including Elsevier Science, John Wiley and Sons, then Academic Press, Blackwell Publishing, and then Springer Verlag, with which the consortium of national university libraries began to negotiate in pursuit of the "Big Deal," namely of the access to whole collection, resulting in successful agreements with publishers beginning in 2002.

3) The increase of requests after 2000 on for articles published in "domestic" journals is largely explained by the increase in request for articles in such fields as nursing, genontology, clinical psychology, and school counseling. Publishing in such fields has not fully matured in spite of the current focusing in higher education 


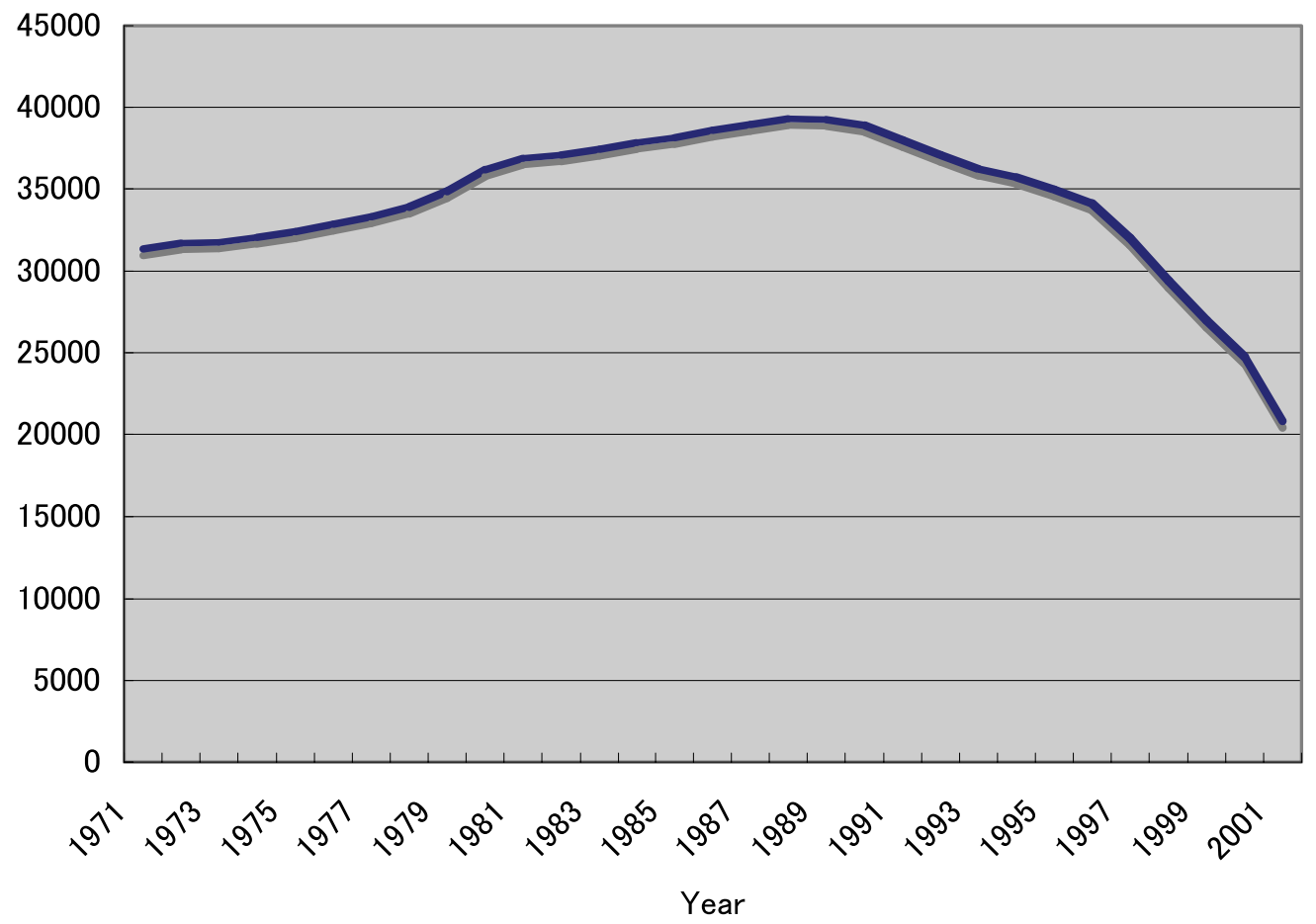

Fig. 8 Number of foreign journal titles(unique titles) available in Japanese university libraries.

Note: The number is that of different title kinds, i.e., the duplicated copies of the same title are collapsed to one title kind. The counting was done by Akira Miyazawa, NII, at the end of the calendar year of 2002, based on the NACSIS/NII's union catalog for bibliographical and holding records in almost all Japanese university libraries, created collaboratively since 1980s. It has been observed that university libraries' data entering practice does not guarantee the holding records of the most recent years to be reflected in the union catalog on real time basis, so the numbers for 2002 and 2001 must be viewed with caution.

on starting new schools and departments in response to national demands to cope with the ageing society and the problems in elementary and secondary schools.

In support of observation 1), Fig. 8 shows the rapid shrinking of the variety of journal titles available in Japanese university libraries, where the almost 40,000 titles were reduced to nearly 20,000 in 10 years. The titles whose articles were requested in 1990s are mostly those published by foreign publishers at high prices.

Observation 2) is corroborated by the kind of titles whose articles are much less requested than in the 1990s and the decrease in the number of filled requested supplied by the "foreign journal center" libraries, which in the 1990s played an important role in meeting the need from medical faculties and researchers. Titles published by Elsevier and Wiley in the field of medicine and chemistry have disappeared from the list of heavily requested titles since 2000. Typical examples include Genomics, Langmuir and Oncogene. The number of requested filled by Life Science Library, Osaka University, which is still a center for medical and biological information nationwide, decreased from more than
50,000 around 2000 to less than 30,000 in 2005. Tokyo Institute of Technology Library have continued to supply the same number of photocopied articles to participating libraries, but this is due to the fact the most of the requests for the library is for proceedings papers in engineering and applied sciences, which have not benefited from consortial deal with publishers.

The dramatic change in the information environments on national university campuses is obviously a result of libraries' consortial efforts starting from 2000 and the government's incentive funding to individual libraries from 2002 to 2004 but the details of the situation must be further investigated in a different research.

Observation 3) deserves discussion in a separate section which follows.

\subsubsection{Heavy demand for journals in nursing science and related areas}

The currently heavy demands for articles published in domestic journals in nursing science and related areas are conspicuous. Yoneda et al. [15] also discussed factors affecting the recent increase of document de- 
mands in nursing science at Chiba University Health Sciences Library, based on its local and NACSIS-ILL statistics. They point out that the influential factors are 1) increase of new nursing schools at graduate and undergraduate level, which led to increase of research activities and researchers, which in turn naturally create demands for documents, 2) expansion of the journal title coverage in NDL's Zasshi kiji sakuin[Japanese Periodicals Index], which facilitated awareness the existence of published articles in nursing science, 3) increase of document demands on the part of nursing practitioners who seek advanced qualifications. In addition, while many colleges and departments specializing in nursing science are newly being established all over the country, back issues of relevant journals are hardly available either because they tend to be distributed only to the membership of publishing societies or as they are simply conference proceedings or internal reports both of which are hard to acquire in the market. Further research is again required to grasp the overall situation and tendencies and also to understand information needs and information seeking behavior in the field of nursing science to maximize available resources and to create new information environment to support their research and practice effectively.

As retrospective digitization of domestic journal articles has not developed to a noticeable extent, researchers still heavily rely on ILL services to satisfy their information need, particularly in social science and humanities or some specific areas, in which domestic journals are important sources for research information.

The propagation of NACSIS-ILL system in scale obviously has contributed to the increased number of photocopy requests for domestic journals, which is to be explained by the correlation between requests of photocopy for articles published in domestic journals and the number of participating institutions of NACSIS-ILL, where $\mathrm{r}=0.931$.

\subsubsection{Emergence of small or middle-sized libraries as source of document supply}

The Emergence of small or middle-sized libraries as source of document supply is obviously related to increasingly heavy demands for journals in nursing science. In fact, a limited range of university/college libraries holding relatively rich collections in nursing science and social welfare supply photocopies to many requesting libraries, while strangely libraries in prestigious universities don't. In addition, there is a possibility that the extension of offset accounts arrangement and changes of pricing policy, in which every national university library used to charge the same fee per page in photocopies, could change the structure in ILL. Fur- ther observation is required on the matter, because the new offset accounts arrangement was established only in 2004.

\subsubsection{Why so efficient?}

Improved turnaround time is only possible with good library service assisted by reliable nationwide postal system. Library service cannot become improved without librarians' awareness of the importance ILL/DD services in the overall scheme to meet research needs for documents and their expertise in its operation. Although this much is obvious, there has not been any convincing argument that shows why such an efficient system has been realized in Japan in this particular period.

\section{Conclusion}

It should be concluded that the currently NII's NACSIS-ILL system has successfully contributed to the operation of interlibrary loan and document delivery(ILL/DD) among Japanese university libraries since 1994 to Japanese researchers' general satisfaction, mainly evidenced by growth in number both of transactions and of participating libraries, increasingly higher fill rates and ever shorter turnaround time.

While achieving the originally aimed goals of efficiently sharing scientific information among university libraries, particularly documents collected in "foreign journal centers" and some major university libraries, university library community has experienced sea change, almost without knowing it, as a result of the advent of the age of electronic, online journals and the new era of Japanese higher education, namely incorporation of higher learning institutions and shift in research interest to socially relevant issues, like comedical practices and clinical psychology. Online journals have enabled libraries as well as publishers to maximize accessibility on campus to scientific publications, changing the concept of unit cost from that per copy to that per download, the latter of whose marginal cost could be literally minimal.

Consortial deals between libraries and publishers in Japan and the rest of the world in the early 2000s have brought about an environment in which the consituency of campus has unlimited access to virtually all English scientific publications "in print," though under budget constraints. The current situation so described does not require interlibarary arrangement for access to journal article contents and it is perfectly reflected in trends observed in the statistics we have discussed in this paper.

The sea change in question has not been brought to attention because the statistics provided by NACSIS and currently by NII have rather concentrated on illustrating the growth of ILL/DD in Japan in general than 
analyzed the details of the trends hidden behind the total number of transactions. The lacuna resulting from the decrease in request for foreign articles have been quickly filled up almost coincidentally by the increase in request for domestic articles written in Japanese in a limited range of research fields whose value in societal commitment of universities have come to be appreciated recently on campus as well as in society at large.

This change also led to the structural change of ILL, where small or middle-sized university libraries noticeably began to supply for the photocopies of articles in domestic journals mainly in the subject of nursing science. It can be said that the purpose of ILL in Japan has been shifted from the provision of articles published in foreign journals to those in domestic journals.

Further policy actions should be sought to improve the accessibility to domestic journals, in particular to those heavily requested titles observed in Table 4 in recent years. As shown in Table 4, almost a fourth of photocopy requests for articles published in domestic journals are satisfied by top 300 journal titles, so these titles would be the first target to be taken into account for further actions, i.e. the cooperative digitization and sharing with libraries as many as possible, in order to widen the accessibility.

This is the first study on ILL/DD activities in Japanese university libraries community. Although it has contributed certain findings on characteristics and problems on researchers' information demands and the information provision to meet their needs, at the same time, need for further in-depth studies has come to be more realized in order to understand information needs and information seeking behavior in particular subjects such as nursing science where heavy ILL demands are observed in order to maximize the currently available resources and to create new information environment to effectively support their research and practice.

\section{Acknowledgement}

The study underlying this paper is partly supported by Grand-in-Aids for Scientific Research, "Reengineering of the Functionalities of Research Libraries in the Digital Milieu"(abbreviated as REFORM)(20042006). We gratefully acknowledge the National Institute of Informatics for their enabling us to analyze the NACSIS-ILL log files, particularly Jun Adachi, Akira Miyazawa, Kazunobu Konishi, Koichi Ojiro, Takashi Oba, Riko Modeki, Yukino Aihara, Kazuyuki Uzawa, Hiroshi Ogiwara, Ayano Hattori for their useful comments at the review meetings and support in data provision. We also owe to all REFORM colleagues for their comments and suggestions, and Megumi Kurokawa and Junko Arao for their secretarial assistance. In addition, special thanks should be given to Hisafumi Tanaka and
Hiroyuki Amenomori for their sharing a rather longer time for interviews on the Monbusho's policy and activities for university libraries in Japan during 1970s and 80 s.

\section{Cited works}

[1] Y. Tsuda, "Igaku joho nettowaku to Nihon Igaku Toshokan Kyokai [Medical information network and Japan Medical Library Association]," Library and Information Science, no.9, pp.343-359, 1971. (in Japanese)

[2] Japan Medical Library Association, Nihon Iigaku Toshokan Kyokai rokujunen ryakushi [60 year history of Japan Medical Library Association], Tokyo, Japan Medical Library Association, 1989, 350p. (in Japanese)

[3] Gakujutsu Shingikai[Scientific Research Council], Kongo ni okeru gakujutsu joho shisutemu no arikata ni tsuite [A Proposal for academic information system in future], 1980. (in Japanese) Text is also reproduced in Daigaku toshokan kenkyu [Journal of college and university libraries], vol.16, pp.57-66, 1980. (in Japanese)

[4] J. Tamura, "Daigakukan ILL no atarashii tenkai ni mukete[New direction of ILL among university libraries]," Joho no kagaku to gijutsu[The journal of information science and technology association], vol.41, no.3, pp.230-236, 1991. (in Japanese)

[5] K. Konishi and S. Kai, "Daigaku toshokan sabisu no kasseika ni mukete: Gakujutsu Joho Senta ILL shisutemu no gaiyo[Toward the promotion of university library services: overview on NACSIS-ILL]," Joho kanri [Journal of information processing and management], vol.35, no.5, pp.192-204, 1992. (in Japanese)

[6] M. Shibayama, et.al., "Gakujutsu joho shisutemu to daigaku toshokan nettowaku[Science Information System and university library network in Japan]," Joho no kagaku to gijutsu[The journal of information science and technology association], vol.46, no.6, pp.511-516, 1993. (in Japanese)

[7] S. Kai, "Gakujutsu joho senta ILL shisutemu no riyo jokyo to toshokan kyoryoku[NACSIS-ILL usage and library cooperation in Japan]," Daigaku toshokan kenkyu[Journal of college and university libraries], vol.41, pp.1-16, 1993. (in Japanese)

[8] Y. Hashi, "NACSIS-IR, ILL sabisu no mondaiten[Problems on NACSIS IR and ILL]," Daigaku toshokan kenkyu[Journal of college and university libraries], vol.44, pp.15-30, 1994. (in Japanese)

[9] National Institute of Informatics. NACSIS-ILL statistics: http://www.nii.ac.jp/CAT-ILL/contents/nill_top. html (accessed 2006-09-01) (in Japanese)

[10] MEXT. Gakko kihon chosa, Heisei 17nendo[Statistical Abstract, 2005]. http://www.mext.go.jp/b_menu/toukei/ 
001/05122201/002/001/001.htm (accessed 2006-09-01) (in Japanese)

[11] MEXT. Daigaku toshokan jittai chosa kekka hokoku, Heisei 16nendo[Library statistics of colleges and universities, 2004-2005]. http://www.mext.go.jp/b_menu/ toukei/001/05070501.htm (accessed 2006-09-01) (in Japanese)

[12] M. Jackson, Measuring the performance of interlibrary loan operations in North American research and college libraries, ARL, Washington, D.C., 1998.

[13] M. Jackson, Assessing ILL/DD services: New costeffective alternatives, ARL, Washington, D.C., 2004, $154 \mathrm{p}$.

[14] Y. Sakai and M. Sonohara, "ILL tokei deta bunseki karamita igaku bunken ryutsu niokeru shidai igaku toshokan no yakuwari[Statistical analysis of interlibrary loan services: a case study at a medical library in a Japanese private university]," Igaku toshokan[Medical library], vol.53, no.3, pp.233-238, 2006. (in Japanese)

[15] N. Yoneda, et.al., "Big deal go no ILL: Chiba Daigaku Fuzoku Toshokan Inohana bunkan ni okeru chosa [ILL photocopy services under Big Deal: a case study on Library of Health Sciences(Inohana Library), Chiba University]," Daigaku Toshokan Kenkyu[Journal of college and university libraries], vol.76, pp.74-81, 2006. (in Japanese)

\section{References}

- Gakujutsu Shingikai[Scientific Research Council], Kongo ni okeru gakujutsu joho shisutemu no arikata ni tsuite (chukan hokoku) [Improvement of the science information system: in perspective, the intermediate report of the Scientific Research Council, 1979]. (in Japanese) Text is also reproduced in Daigaku toshokan kenkyu [Journal of college and university libraries], vol.15, pp.29-52, 1979.

- H. Ishii, "Shigen kyoyu no shintenkai to ILL/DD[Perspective of interlibray loan: New direction of library resource sharing and perspective of ILL/DD service]," Joho no kagaku to gijutsu[The Journal of information science and technology association], vol.49, no.8, pp.378-386, 1999. (in Japanese)

- M. Kimura, "Bunken fukusha moshikomi ni taisuru shazetsu: Okayama daigaku fuzoku toshokan nogyo seibutsu kenkyujo bunkan ni okeru shazetsu no jitsujo[Declinations of requests of document reproductions: a case study on the branch library of Institute for Agricultural and Biological Sciences, Okayama University Library]," Daigaku toshokan kenkyu[Journal of college and university libraries], vol.25, pp.77-83, 1984. (in Japanese)

- K. Kurihara, et. al., "Daigaku kyokan no gakujutsu zasshi riyo to toshokan keikaku[Library planning and periodicals usage in university libraries]," Daigaku toshokan kenkyu[Journal of college and university libraries], vol.19, pp.45-57, 1981. (in Japanese)
- H. Nagata, "Daigaku toshokan ni okeru dokyumento deribari sabisu[Document delivery services in university libraries]," Joho no kagaku to gijutsu[The Journal of information science and technology association], vol.39, no.7, pp.231-239, 1989. (in Japanese)

- H. Nagayoshi, "Kyushu chiku kokuritsu daigaku ni okeru gaikoku zasshi konyu jokyo chosa[Survey on scholarly journal subscriptions in national universities in Kyoshu area]," Daigaku toshokan kenkyu[Journal of college and university libraries], vol.15, pp.61-66, 1979. (in Japanese)

- D. Oertel, "Doitsu no daigaku ni okeru ruikei no henka to kyoryoku taisei no hatten[The change of pattern German university libraries and the development of their co-opreation]," Daigaku toshokan kenkyu[Journal of college and university libraries], vol.15, pp.53-60, 1979. (in Japanese)

- T. Suzuma, "Shakai kagakukei gaikoku zasshi senta ni tsuiteno oboegaki[Note on subject foreign journal center in social science]," Daigaku toshokan kenkyu[Journal of college and university libraries], vol.35, pp.48-55, 1990. (in Japanese)

- T. Welch, Toshokan: libraries in Japanese community, London, Bingley, 1976, 306 p.

- Y. Yamada, "Shakai kagakukei kyoten toshokan no gaikoku zasshi shushu ni tsuite[collection development at a subject foreign journal center in social science]," Daigaku toshokan kenkyu[Journal of college and university libraries], vol.29, pp.63-67, 1986. (in Japanese)

- Y. Yanase, "Bunken fukusha gyomu kaizen no kokoromi: Fax fukyu jidai o mukaete[Toward the improvement of ILL services]," Daigaku toshokan kenkyu[Journal of college and university libraries], vol.38, pp.91-103, 1991. (in Japanese)

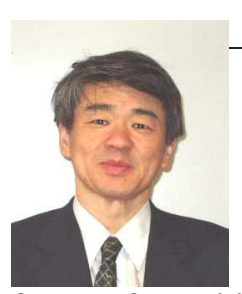

\section{Syun TUTIYA}

B.A. and M.A. from the University of Tokyo, 1975 and 1977, respectively. After graduate studies in philosophy at the University of Tokyo, appointed at Chiba University associate professor of philosophy in 1982, and professor of cognitive and information sciences in 1994, serving as university librarian from 1998 to 2002, and from $2004 \mathrm{on}$. His current interests include the philosophy of mind and language, the history of logic, the history of science and engineering, document processing, scholarly communication and publishing. 


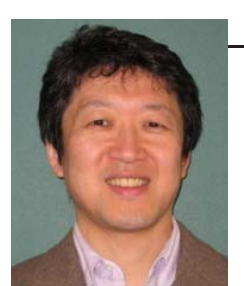

\section{Hiroya TAKEUCHI}

B.A. and M.A in Library and Information Science from Keio University in 1985 and 1987, respectively. After having been experienced in both library practice and teaching, appointed at Chiba University as associate professor of library and information science in 2003. He also serves as research fellow at the Library Innovation Center attached to Chiba University Library. His research interests include information policies, university library management and services, and scholarly communication.

\section{Yoshinori SATO
Received Ph.D. from the University of Library and Information Science in 2003, and has been working at Mie University as a Professor of Library and Information Science since 2005. He had been working in academic li- braries for 20 years. His current research areas include evaluation of library and information services, schol- arly communication and information usage, and digital archives.}

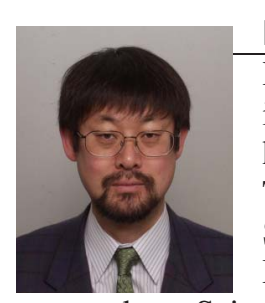

\section{Hiroshi ITSUMURA}

Received B.A. from Keio University in 1980 and M.L.I.S. 1987. and has been working at University of Tsukuba as Professor of Graduate School of Library Information and Media Studies since 2006. He is also engaged as Scientific Research Senior Specialist of the Research Promotion Bureau in MEXT(Ministry of Education, Culture, Sports, Science and Technology) since 2002. His current interests include the management and services of academic university, information search behavior and scholarly communication. 